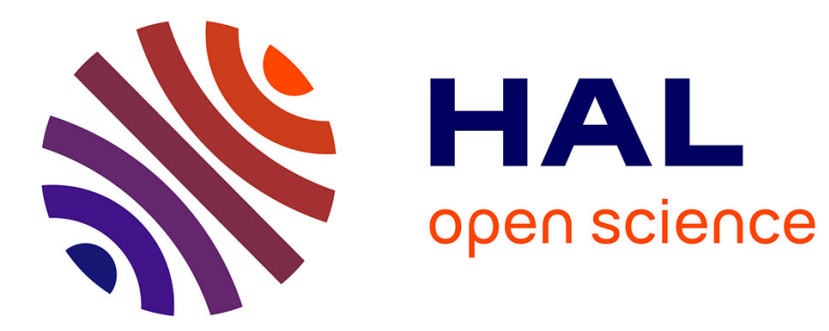

\title{
Temperature influence on water transport in hardened cement pastes
}

\author{
Emeline Drouet, Stéphane Poyet, Jean-Michel Torrenti
}

\section{To cite this version:}

Emeline Drouet, Stéphane Poyet, Jean-Michel Torrenti. Temperature influence on water transport in hardened cement pastes. Cement and Concrete Research, 2015, 76, pp.37-50. 10.1016/j.cemconres.2015.05.002 . cea-01272801

\section{HAL Id: cea-01272801 https://hal-cea.archives-ouvertes.fr/cea-01272801}

Submitted on 11 Feb 2016

HAL is a multi-disciplinary open access archive for the deposit and dissemination of scientific research documents, whether they are published or not. The documents may come from teaching and research institutions in France or abroad, or from public or private research centers.
L'archive ouverte pluridisciplinaire HAL, est destinée au dépôt et à la diffusion de documents scientifiques de niveau recherche, publiés ou non, émanant des établissements d'enseignement et de recherche français ou étrangers, des laboratoires publics ou privés. 


\section{in hardened cement pastes.}

${ }^{a}$ CEA, DEN, DPC, SECR, Laboratoire d'Etude du Comportement des Bétons et des Argiles, F-91191 Gif sur

5 Yvette Cedex, France.

6 b Université Paris-Est, IFSTTAR, Département Matériaux \& Structures, 14-52 boulevard Newton, F-77447

7 Marne la Vallée cedex 2, France.

\section{Abstract}

9 Describing water transport in concrete is an important issue for the durability assessment of radioactive waste management reinforced concrete structures. Due to the waste thermal output such structures would be submitted to moderate temperatures (up to $80^{\circ} \mathrm{C}$ ). We have then studied the influence of temperature on water transport within hardened cement pastes of four different formulations. Using a simplified approach (describing only the permeation of liquid water) we characterized the properties needed to describe water transport (up to $80^{\circ} \mathrm{C}$ ) using dedicated experiments. For each hardened cement paste the results are presented and discussed. 
 \\ 1. Introduction}

18 Water plays a very important role in concrete structures durability. This fact is well illustrated by the

results of Tuutti [1] which relate the variations of the corrosion current of steel embedded in a carbonated mortar as a function of the external relative humidity $(\mathrm{RH})$. In a more general way water is necessary for the chemical reactions to occur (in solution) and presents a significant impact on concrete transport properties. The durability assessment of concrete structures thus necessitates an accurate description of water transport all along service life. Among the data needed to compute water flow in unsaturated conditions, the water sorption isotherm and permeability are the most important (see part 2). In the field of radioactive waste management, the concrete structures and containers would also have to cope with heating due to the waste thermal output (the maximal temperature to be reached is $\left.80^{\circ} \mathrm{C}\right)$

It has been known for long that water transport is strongly influenced by temperature. Experiments performed on cementitious materials have shown that the higher the temperature, the faster the water transport [2-9]. Several authors used the diffusion equation to describe isothermal drying experiments. In so doing, the resulting moisture diffusivity $D$ was found to increase with temperature. Glover and Raask [4] showed the moisture diffusivity of a Portland cement paste (water-to-cement ratio $w / c=0.28$ ) was multiplied by 11 to 15 between 30 and $70^{\circ} \mathrm{C}$ whereas Wong et al. [7] obtained a factor 6 to 8 between 20 and $40^{\circ} \mathrm{C}$ for three concretes (Portland cement, w/c $=0.4,0.5$ and 0.6 ). In the same way Powers [5] measured the permeability of Portland cement pastes ( $\mathrm{w} / \mathrm{c}$ from 0.5 to 0.8 ) between 0 and $27^{\circ} \mathrm{C}$ using water. The resulting hydraulic conductivity (that depends on water viscosity, in $\mathrm{m} / \mathrm{s}$ ) was found to increase by a factor 3. Hughes et al. [2] and Hancox [3] dried Portland cement paste samples $(w / c=0.3$ and 0.5$)$ at temperatures ranging from 21 to $95^{\circ} \mathrm{C}$. The diffusivity increase with temperature was found to follow Arrhenius' equation. The mean activation energy was $43 \mathrm{~kJ} / \mathrm{mol}(10.2 \mathrm{kcal} / \mathrm{g} / \mathrm{mol})$. 
It must be mentioned that smaller increase in water transport properties were obtained in recent

41 studies. Jooss and Reinhardt [9] measured water permeability and diffusivity of several different

42 cementitious materials (using water permeametry and cup method). They found that permeability and

43 diffusivity were only increased by $18-92 \%$ and $18-41 \%$ respectively between 20 and $80^{\circ} \mathrm{C}$. Černy et al. [8]

44 used the so-called PCK method (similar to an imbibition test) to estimate the moisture diffusivity of two

45 concrete used for nuclear power plants containment building in France and Czech Republic. The values

46 obtained at $80^{\circ} \mathrm{C}$ were greater than the ones obtained at $5^{\circ} \mathrm{C}$ by a factor $2.0-2.5$.

47 Temperature is also known to affect the water retention properties of cementitious materials [6, 10-15].

48 A temperature increase leads to the reduction of the amount of water retained at equilibrium with a

49 given $\mathrm{RH}$ : the greater the temperature increase, the more the reduction. For instance for a high-

50 performance concrete kept at $60 \% \mathrm{RH}$, increasing temperature from 30 to $80^{\circ} \mathrm{C}$ led to the reduction of

51 the water content (by mass) at equilibrium from $3 \%$ to about $1 \%$ [13]. The isotherm shape is also

52 modified; the water content reduction is not constant over the RH-range. It depends on the temperature

53 increase. Another important point is the absence of temperature threshold: any change in temperature

54 is expected to impact the water retention curve.

55 The influence of temperature is generally attributed to the variation of water physical properties (density

56 and surface tension) [16] as well as the coarsening of the pore structure in relation to ettringite

57 dissolution and C-S-H alteration [14]. It was however suggested recently that another phenomenon

58 might be at work [13]. A temperature change at a constant $\mathrm{RH}$ leads to the shift of equilibrium between

59 the adsorbed phase and water vapor. Since adsorption is an exothermic process, a temperature increase

60 shifts the equilibrium towards the endothermic reaction (that is to say desorption). Consequently water

61 is released. A simple tool was then proposed to describe this so-called "thermal desorption" [17]. It is

62 based on Clausius-Clapeyron equation [18]: 


$$
q_{s t}(w)=-\left.R \frac{\partial \ln \left(p_{v}\right)}{\partial\left(\frac{1}{T}\right)}\right|_{w}
$$

64

where:

- $R$ is the universal gas constant $(8.3145 \mathrm{~J} / \mathrm{mol} / \mathrm{K})$;

- $p_{v}$ vapor pressure $(\mathrm{Pa})$ at equilibrium with the water content $w$;

- $\quad T$ absolute temperature (K);

- $q_{s t}$ isosteric energy $(\mathrm{J} / \mathrm{mol})$.

$q_{s t}$ corresponds to the amount of heat involved in the adsorption process $(\mathrm{J} / \mathrm{mol})$. Note that in eq. (1) the derivation operation must be carried out for a constant amount of adsorbed water $w$. The isosteric energy $q_{s t}$ can be obtained using two isotherms at two distinct temperatures. Once $q_{s t}$ is known, the water retention curve for any arbitrary temperature $T$ can be easily estimated using:

$$
h(w, T)=h\left(w, T_{0}\right) \frac{p_{v s}\left(T_{0}\right)}{p_{v s}(T)} \exp \left[q_{s t}(w) \frac{T-T_{0}}{R T T_{0}}\right]
$$

where:

- $p_{v s}(T)$ is the vapor pressure at saturation $(\mathrm{Pa})$ for the absolute temperature $T$;

- $h(w, T)$ relative humidity at equilibrium with the water content $w$ at the absolute temperature $T$.

This simple model was found to satisfactorily reproduce the temperature-induced evolution of concrete water retention curve $[13,17]$. This model implicitly assumes that the shift of equilibrium is the only mechanism at work and that the microstructure modifications can be neglected.

For the description of unsaturated water transport, the intrinsic permeability is commonly evaluated through inverse analysis [19-22]: the temperature-induced modifications of the water retention curve described above are then expected to have a significant influence on the permeability assessment [23]. The main objective of this study was to assess the influence of temperature on unsaturated permeability. 
With regards to Andra's (the French agency for radioactive waste management) requirements in the context of nuclear waste storage, we have designed an experimental campaign to acquire all the data needed to describe unsaturated water transport using a simplified model (see section 2) and cementitious materials of interest. The results do constitute a unique and consistent dataset.

\section{Background}

Water transport within porous media involves three different motions: (1) permeation of the liquid water; (2) permeation of the gaseous phase (water vapor + dry air) and (3) diffusion of water vapor within the gaseous phase. The neat description of these phenomena leads to three coupled differential equations $[20,21,24-27]$. The major drawback of such an approach is the very large number of input data that are difficult to acquire experimentally.

From a practical point of view, water transport can be profitably described in a simplified way using a single equation accounting for liquid permeation only. The others motions (permeation of the gaseous phase and water vapor diffusion) are neglected. This assumption was found to be valid for a hardened cement paste $(\mathrm{w} / \mathrm{c}=0.35)$ with a permeability equal to $1.0 \times 10^{-21} \mathrm{~m}^{2}[20]$. In a recent study Thiery et al. $[28,29]$ estimated the respective contribution of each motion to the overall water flow. They showed that the assumption validity domain depends on the material properties and especially on permeability. For a high-performance concrete $(\mathrm{w} / \mathrm{c}=0.27)$ with low permeability $\left(2 \times 10^{-22} \mathrm{~m}^{2}\right)$ the assumption is valid between $\mathrm{RH}=20 \%$ and $100 \%$ whereas it is only valid between $\mathrm{RH}=65 \%$ and $100 \%$ for a low-strength concrete $(\mathrm{w} / \mathrm{c}=0.84)$ with high permeability $\left(4 \times 10^{-19} \mathrm{~m}^{2}\right)$.

The liquid water flow rate is given by the extension of Darcy's law for incompressible unsaturated media [30]: 
106 In which:

- $\quad \eta$ is the water viscosity [Pa s];

- $\quad \rho$ water density $\left[\mathrm{kg} / \mathrm{m}^{3}\right]$;

- $\quad K$ intrinsic permeability $\left[\mathrm{m}^{2}\right]$;

- $\quad k_{r}$ relative permeability to water [without unit];

- $\quad P$ water pressure [Pa].

In unsaturated conditions the water pressure presents negative values $P \in]-\infty ; 0]$. It is evaluated using Kelvin-Laplace equation:

$$
P=-\rho \frac{R T}{M} \ln (h)
$$

where $M$ is the water molar mass $[0.018 \mathrm{~kg} / \mathrm{mol}]$.

The mass conservation equation writes:

$$
\frac{\partial}{\partial t}(\rho \emptyset S)=-\operatorname{div}\left(\underline{j}_{w}\right)=-\operatorname{div}\left[-\rho K \frac{k_{r}}{\eta} \operatorname{grad}(P)\right]
$$

In which

- $S$ is the saturation index [without unit], it characterizes how pores are filled (by volume) with liquid water. It ranges between 0 (dry state) and 1 (saturated state).

- $\varnothing$ is the concrete porosity [volume per volume, without unit].

In isothermal conditions (as this is the case in this study, see after) and assuming that water is incompressible and that water flow is the only phenomenon at work (absence of dissolution or precipitation), $\rho$ and $\emptyset$ can be considered as constants. The following equation is obtained: 


$$
\varnothing \frac{\partial S}{\partial t}=\operatorname{div}\left[K \frac{k}{\eta} \operatorname{grad}(P)\right]
$$

$$
k_{r}=\sqrt{S}\left[1-\left(1-S^{\frac{1}{m}}\right)^{m}\right]^{2}=\left[1+\left(\frac{|P|}{P_{0}}\right)^{\frac{1}{1-m}}\right]^{-\frac{m}{2}}\left\{1-\left(\frac{|P|}{P_{0}}\right)^{\frac{1}{1-m}}\left[1+\left(\frac{|P|}{P_{0}}\right)^{\frac{1}{1-m}}\right]^{-m}\right\}^{2}
$$

138 The left-hand term $\left(\frac{\partial S}{\partial P}\right)$ of equation (7) is given by:

139

$$
\varnothing\left(\frac{\partial S}{\partial P}\right) \frac{\partial P}{\partial t}=\operatorname{div}\left[K \frac{k}{\eta} \operatorname{grad}(P)\right]
$$

This simple equation allows the water transport description within the cementitious materials knowing only four their properties, namely: the porosity $\emptyset$, the derivative of the capillary pressure function, the intrinsic and relative permeability $K$ and $k_{r}$. Following Savage and Janssen [31] the water retention curve is almost described using the equation proposed by van Genuchten [32]:

$$
S=\left[1+\left(\frac{|P|}{P_{0}}\right)^{\frac{1}{1-m}}\right]^{-m}
$$

where $P_{0}$ and $m$ are two positive parameters: $m$ (usually around 0.5 ) [without unit] whereas $P_{0}$ is equivalent to a pressure [several tenths of MPa]. The use of Mualem's model [33] together with eq. (8) allows deriving an analytical expression for the relative permeability $k_{r}$ (the value of the parameters $m$ and $P_{0}$ are the same as above):

$$
\left(\frac{\partial S}{\partial P}\right)=\frac{m}{(m-1) P_{0}}\left(\frac{|P|}{P_{0}}\right)^{\frac{1}{1-m}}\left[1+\left(\frac{|P|}{P_{0}}\right)^{\frac{1}{1-m}}\right]^{-1-m}
$$




\section{Methods}

141

\subsection{Materials}

We used hardened cement pastes prepared using four different binders that were selected for their potential interest for radioactive waste management in France:

- The CEM I 52.5 R CE PM-ES-CP2 (according to the European standard EN-206) from Val d'Azergues factory (France, Lafarge). This ordinary Portland cement (OPC) was selected by Andra (the French Agency for radioactive waste management) as a reference cement for the study of concrete structures and waste packages.

- The CEM II/B-LL 42.5 N CE CP2 from Le Teil factory (France, Lafarge). This cement (OPC + 25\% limestone filler) was selected because it was used for the realization of a scale-one subsurface storage structure mockup (Galatée) [34-36].

- The CEM V/A (S-V) 42.5 N CE PM-ES-CP1 from Airvault factory (Calcia, France). This cement was selected by Andra as a reference binder for concrete packages.

- A low-alkanity ternary mix of CEM I/OPC (37.5\%), silica fume (32.5\%) and fly ash (35\%). The cement used in this mix was provided by Lafarge, Le Teil factory, France (CEM I 52.5 N CE PMES). The silica fume and fly ash were provided by Condensil (S 95 DM) and Calcia respectively. This mix composition was designed in the field of geological disposal by $[37,38]$ to mitigate the heat emitted during hydration and limit the chemical interaction between clay minerals and concrete parts (alkaline plume) which could impair clay physical and chemical properties.

A unique water-to-binder ratio $(\mathrm{w} / \mathrm{b})$ was used to enable comparison between the four pastes. We chose $w / b=0.40$ because it allowed the CEM I paste to be representative of the concrete studied in [13]. The resulting hardened cement paste is the same as the one embedding the concrete aggregates. For this 
purpose, the paste water to binder ratio $\mathrm{w} / \mathrm{b}$ was adjusted to account for the water brought by the

163 superplasticizer and absorbed by the aggregates. Moreover this value appeared to yield good properties

164 of each fresh paste (good workability, neither visible segregation nor bleeding). The composition of each 165 paste is given in Table 1.

Table 1. Composition of the pastes.

\begin{tabular}{llllll}
\hline Compound & CEM I & CEM II & CEM V & Low-pH & Unit \\
\hline OPC & 1396 & 1023 & 759 & 468 & g/L of paste \\
Calcareous filler & - & 341 & - & - & g/L of paste \\
Slag & - & - & 298 & - & g/L of paste \\
Fly ash & - & - & 298 & 377 & g/L of paste \\
Silica fume & - & - & - & 405 & g/L of paste \\
Water & 558 & 545 & 542 & 500 & g/L of paste \\
Superplasticizer & - & - & - & 12.5 & g/L of paste \\
\hline
\end{tabular}

167

168 The four pastes were prepared in the laboratory in ten consecutive batches (two liters each) spanning

169 over three days. Each specimen was cast in a cylindrical mold $(\varnothing 35 \times \mathrm{H} 60 \mathrm{~mm}$ for water adsorption

170 experiments and $\varnothing 51 \times \mathrm{H} 80 \mathrm{~mm}$ for permeability assessment experiments) which was then hermetically

171 closed and kept at $20^{\circ} \mathrm{C}$ for seven days before unmolding. All the specimens of the same formulation

172 were immersed in a special curing solution inside an air-tight chamber (to prevent carbonation) for three

173 months. The composition of the curing solution was adjusted to prevent calcium and alkalis leaching. For

174 the CEM I, CEM II and CEM V pastes we determined the curing solution composition by expression of the

175 pore solution [39] and analysis using ionic chromatography (Table 2). The samples used for extraction

176 were kept three months in sealed bags (rather than under water to prevent dilution of the alkalis).

177 Analysis of the solutions at the beginning and end of the cure showed limited change (Table 2). 


\begin{tabular}{ccccccccccccc} 
& \multicolumn{4}{c}{ CEM I } & \multicolumn{4}{c}{ CEM II/B } & \multicolumn{3}{c}{ CEM V/A } \\
\cline { 2 - 14 } & $\mathrm{Na}^{+}$ & $\mathrm{K}^{+}$ & $\mathrm{Ca}^{2+}$ & $\mathrm{pH}$ & $\mathrm{Na}^{+}$ & $\mathrm{K}^{+}$ & $\mathrm{Ca}^{2+}$ & $\mathrm{pH}$ & $\mathrm{Na}^{+}$ & $\mathrm{K}^{+}$ & $\mathrm{Ca}^{2+}$ & $\mathrm{pH}$ \\
\hline Interstitial solution & 47 & 452 & 2 & 13.7 & 91 & 94 & 1 & 13.2 & 87 & 533 & 2 & 13.7 \\
Begining of cure & 49 & 439 & 2 & 13.6 & 90 & 93 & 3 & 13.3 & 90 & 518 & 4 & 13.7 \\
End of cure & 54 & 455 & 3 & 13.6 & 96 & 95 & 5 & 13.2 & 85 & 474 & 2 & 13.7 \\
\hline
\end{tabular}

181 The sodium content of the three cements is quite low (and especially in comparison to the potassium

182 content). This is a direct consequence of the cements composition, low in sodium (Table 3).

Table 3. Chemical composition of the cements.

\begin{tabular}{ccccccccccccc} 
& $\mathrm{SiO}_{2}$ & $\mathrm{Al}_{2} \mathrm{O}_{3}$ & $\mathrm{Fe}_{2} \mathrm{O}_{3}$ & $\mathrm{CaO}$ & $\mathrm{MgO}$ & $\mathrm{SO}_{3}$ & $\mathrm{~K}_{2} \mathrm{O}$ & $\mathrm{Na}_{2} \mathrm{O}$ & $\mathrm{MnO}$ & $\mathrm{TiO}_{2}$ & LOI & INS \\
\hline $\mathrm{CEM} \mathrm{I}$ & 21.0 & 3.4 & 4.5 & 65.0 & 0.62 & 2.7 & 0.72 & 0.09 & - & - & 1.3 & 0.2 \\
$\mathrm{CEM} \mathrm{II/B}$ & 18.0 & 3.5 & 1.7 & 62.6 & 0.85 & 2.97 & 0.16 & 0.15 & - & - & 9.4 & 1.2 \\
$\mathrm{CEM} \mathrm{V/A}$ & 30.0 & 11.2 & 3.6 & 46.4 & 2.75 & 2.8 & 1.16 & 0.2 & 0.1 & 0.6 & 2.1 & - \\
\hline
\end{tabular}

185 For the Low-pH which pore solution is known to exhibit great concentration variations in the first months

186 of hydration (portlandite is gradually consumed to precipitate new C-S-H: portlandite completely

187 disappears after two months) [38], a different approach was chosen. Several samples were reduced into

188 a rough powder and added to deionized water to generate the curing solution.

189 After the curing period, both ends (top and bottom) of each sample were sawn (using a diamond wire

190 saw with water) and discarded. This resulted in smaller cylinders (

191 experiments and $\varnothing 51 \times \mathrm{H} 60 \mathrm{~mm}$ for permeability assessment experiments) that were assumed to present homogeneous properties versus height [40-42]. Because the specimens were kept under water for three months after casting, full saturation at the cure end was assumed: no additional procedure was thus 
used to ensure initial saturation (for instance saturation under vacuum). It was however verified on a few

195 samples that no water uptake was observed after 48 hours under water and vacuum.

196

\subsection{Mineralogical composition}

The portlandite content was measured using thermogravimetric analysis (TGA). Just after the cure, a specimen was powdered in a $\mathrm{CO}_{2}$-free glove box and $120 \mathrm{mg}( \pm 1 \mathrm{mg})$ were placed in an automated TG analyzer (Netzsch STA 409 PC). The temperature was increased at constant rate $\left(10^{\circ} \mathrm{C} / \mathrm{min}\right)$ under $\mathrm{dry}$ nitrogen flowrate $(60 \mathrm{~mL} / \mathrm{min})$. The portlandite content was computed using the mass loss obtained between 400 and $600^{\circ} \mathrm{C}$.

The C-S-H concentration was estimated following the approach of Olson and Jennings [43] that relates the amount of water adsorbed at $20 \% \mathrm{RH}$ to the $\mathrm{C}-\mathrm{S}-\mathrm{H}$ content. It was then implicitly assumed that the calcium-to-silicon (C/S) ratio of the C-S-H was equal to 1.7. We took advantage of the experimental water retention curves to assess the water content at equilibrium at $20 \%$. The model proposed by Pickett [44] was fitted to the experimental results and used to compute the water content at $20 \%$ (see part 3.4.).

\subsection{Porosity and microstructure}

The specific gravity of the saturated materials $d_{s}$ was measured using the buoyancy method following current recommendations (French standard P18-459:2010): the saturated specimens were weighed under water and in air (using a $1 \mathrm{mg}$ accurate device). In air, the water in excess on the specimen surface was removed using a wet cloth. The measurements were done in an air-conditioned room $\left(20 \pm 2^{\circ} \mathrm{C}\right)$.

The porosity to water $\varnothing$ (by volume) was determined by oven-drying until constant weight; different drying temperatures were used from $20^{\circ} \mathrm{C}$ to $105^{\circ} \mathrm{C}$ for comparison purposes. At $20^{\circ} \mathrm{C}$ and $50^{\circ} \mathrm{C}$ we used silica gel as desiccant $(\mathrm{RH} \approx 3 \%)$ whereas calcium chloride proved to be much more efficient at $80^{\circ} \mathrm{C}(\mathrm{RH}$ measured at $0.0 \%$ using capacitive hygrometer). No desiccant was used at $105^{\circ} \mathrm{C}$ (the RH decrease 
induced by heating at $105^{\circ} \mathrm{C}$ is high enough). A different five-sample set was used for each configuration.

217 Due to the great number of sample-sets all the five specimens were weighed together; this explains why

218 there is no variability information in this case (no standard deviation).

219 The pore-size distribution was characterized using mercury intrusion porosimetry (MIP). Some specimens

220 were first kept a few months in sealed containers above silica gel (at $20^{\circ} \mathrm{C}$ and $50^{\circ} \mathrm{C}$ ) or calcium chloride

221 (at $80^{\circ} \mathrm{C}$ ) to remove most of the evaporable water. They were crushed into pieces (several millimeters

222 thick), freeze-dried using liquid nitrogen and eventually tested (up to $414 \mathrm{MPa}$ ). Three or four replicates

223 were tested for each experiment.

224 The specific surface area of each paste was assessed either directly by MIP or by post-processing the

225 experimental water desorption isotherms using the linear form of the BET model [45]:

$$
\frac{h}{(1-h) w}=\frac{1}{C^{B} w_{m}^{B}}+\frac{C^{B}-1}{C^{B} w_{m}^{B}} h
$$

where $C^{B}$ and $w_{m}^{B}$ are the two BET parameters. $C^{B}$ is related to the energy of the first adsorbed layer and $w_{m}^{B}$ is the water content needed to complete a monomolecular layer. The BET linear form was used to check the validity domain (for which the experimental points follow a straight line). The specific surface area $S_{s}$ was evaluated using the BET monolayer values $w_{m}^{B}$ using [46]:

$$
S_{S}=N_{A} \frac{A_{w}}{\rho V} w_{m}^{B}
$$
$20^{\circ} \mathrm{C}$ ) and $A_{w}$ is the surface area occupied by one water molecule on the sample surface. It was estimated using $[47,48]$ :

$$
A_{w}=1.091\left(\frac{M}{\rho N_{A}}\right)^{\frac{2}{3}}
$$




\subsection{Water retention curves}

237 They were characterized in a classical way using the desiccator method [49] following the protocol used

238 in [13]. Four cylinders $(\varnothing 35 \times \mathrm{H} 50 \mathrm{~mm})$ of each formulation were put in a desiccator above a saturated salt

239 solution for $\mathrm{RH}$ control (sixteen specimens were then introduced into the same desiccator). The

240 specimen dimensions may seem big, but the low specific surface area of the specimens allowed us not to

241 take any precaution against carbonation and to limit the potential impact of sawing (superficial cracking).

242 The main disadvantage was the increase of the time needed to reach hygral equilibrium. We then

243 determined the whole desorption isotherm for each paste by submitting different sets of specimens to

244 different RHs (using different desiccators) simultaneously rather than submitting a unique set to

245 decreasing RH steps. This was expected to induce some variability but it allowed reducing drastically the

246 whole experiment duration.

247 This experiment was conducted at 20,50 and $80^{\circ} \mathrm{C}$. At $20^{\circ} \mathrm{C}$, the desiccators were kept in an air-

248 conditioned room $\left(20^{\circ} \mathrm{C} \pm 2^{\circ} \mathrm{C}\right)$ whereas ovens were used for the two other temperatures: three different

249 ovens were used for $50^{\circ} \mathrm{C}$ and two for $80^{\circ} \mathrm{C}$. At $50^{\circ} \mathrm{C}$ the regulation did not appear to be fully satisfactory:

250 the temperature in the three ovens was found to be ranging from 50 to $60^{\circ} \mathrm{C}$. This is believed to have

251 induced some variability in the isotherm characterization. At $80^{\circ} \mathrm{C}$, the temperature variability was far

252 less than $1^{\circ} \mathrm{C}$. The salt solutions used and the resulting RHs are reported in Table 4.

Table 4. Relative humidity as a function of temperature and saturated salt solution [50-54].

\begin{tabular}{llccc}
\hline \multicolumn{2}{c}{ Saturated salt solutions } & \multicolumn{3}{c}{ Temperature } \\
\cline { 3 - 5 } & & $20^{\circ} \mathrm{C}$ & $50^{\circ} \mathrm{C}$ & $80^{\circ} \mathrm{C}$ \\
\hline Calcium chloride & $\mathrm{CaCl}_{2}$ & $5 \%$ & $3 \%$ & $\approx 0 \%$ \\
Silica gel & $\mathrm{SiO}_{2}$ & $3 \%$ & $3 \%$ & $\approx 10 \%$ \\
Lithium chloride & $\mathrm{LiCl}$ & $11 \%$ & $11 \%$ & $11 \%$ \\
Magnesium chloride & $\mathrm{MgCl}_{2}$ & $33 \%$ & $31 \%$ & $26 \%$ \\
Potassium carbonate & $\mathrm{K}_{2} \mathrm{CO}_{3}$ & $43 \%$ & - & - \\
Magnesium nitrate & $\mathrm{Mg}\left(\mathrm{NO}_{3}\right)_{2}$ & $54 \%$ & - & -
\end{tabular}




\begin{tabular}{llccc} 
Sodium bromide & $\mathrm{NaBr}$ & $59 \%$ & $51 \%$ & $51 \%$ \\
Urea & $\mathrm{CO}\left(\mathrm{NH}_{2}\right)_{2}$ & - & $62 \%$ & - \\
Ammonium nitrate & $\mathrm{NH}_{4} \mathrm{NO}_{3}$ & $63 \%$ & - & - \\
Potassium iodide & $\mathrm{KI}$ & $70 \%$ & $64 \%$ & $61 \%$ \\
Sodium nitrate & $\mathrm{NaNO}_{3}$ & - & $69 \%$ & $65 \%$ \\
Sodium chloride & $\mathrm{NaCl}$ & - & $74 \%$ & $76 \%$ \\
Ammonium sulfate & $\left(\mathrm{NH}_{4}\right)_{2} \mathrm{SO}_{4}$ & - & $79 \%$ & - \\
Ammonium chloride & $\mathrm{NH}_{4} \mathrm{Cl}$ & $80 \%$ & - & - \\
Potassium chloride & $\mathrm{KCl}$ & - & - & $80 \%$ \\
Potassium nitrate & $\mathrm{KNO}_{3}$ & - & $85 \%$ & - \\
Sodium carbonate & $\mathrm{Na}_{2} \mathrm{CO}_{3}$ & - & - & $85 \%$ \\
Barium chloride & $\mathrm{BaCl}_{2}$ & $90 \%$ & - & - \\
Sodium sulfate & $\mathrm{Na}_{2} \mathrm{SO}_{4}$ & - & - & $90 \%$ \\
Potassium sulfate & $\mathrm{K}_{2} \mathrm{SO}_{4}$ & $98 \%$ & $96 \%$ & $95 \%$ \\
Deionized water & $\mathrm{H}_{2} \mathrm{O}$ & $100 \%$ & $100 \%$ & $100 \%$ \\
\hline
\end{tabular}

255 Periodically we opened each desiccator, weighed each specimen-set (weighing each sample would have

256 been too much time-consuming) and computed the corresponding relative mass variation to monitor

257 sample drying:

$$
\left(\frac{\Delta m}{m}\right)(t)=\frac{m(t)-m\left(t_{0}\right)}{m\left(t_{0}\right)}
$$

259 where $m(t)$ is the mass for the time $t$ and the mass for the time $t$ (to corresponds to the experiment

260 beginning). The difference from equilibrium was characterized using the following indicator $\varepsilon$ which is an

261 estimator of the relative mass variation curve slope:

$$
\varepsilon(t)=\frac{\left(\frac{\Delta m}{m}\right)(t+1)-\left(\frac{\Delta m}{m}\right)(t)}{\left(\frac{\Delta m}{m}\right)(t)}
$$

263 where $\left(\frac{\Delta m}{m}\right)(t)$ and $\left(\frac{\Delta m}{m}\right)(t+1)$ are the relative mass variations at time $t$ and one day after respectively.

264 From a practical point of view the $\varepsilon$ values were estimated using the equation proposed by Baroghel-

265 Bouny [55] to fit the sample mass loss evolution:

$$
\left(\frac{\Delta m}{m}\right)(t)=\frac{A \sqrt{t}}{B+\sqrt{t}}
$$


where $A$ and $B$ are two parameters to be fitted on the experimental results. The samples were let to

268 equilibrate in their containers as long as possible but they all met the following requirement: $\varepsilon \leq 0.05 \%$

269 (note that many sets of specimens presented lower $\varepsilon$ values at the end of the test). A graphical

270 illustration of this requirement significance is presented on Figure 1 for the CEM I specimens kept at $80^{\circ} \mathrm{C}$

271 and $76 \% \mathrm{RH}$. The criterion was reached after 121 days. Leaving the samples for 121 more days (the

272 equilibration time was then increased by 100\%) brought little improvement: the difference between the

273 relative mass variations at 121 and 242 days is about 3.5\% (relative value). This value was found to be

274 lower than the variability induced by the use of a different sample-set for each $\mathrm{RH}$. The resulting $\varepsilon$ value

275 was then $0.02 \%$.

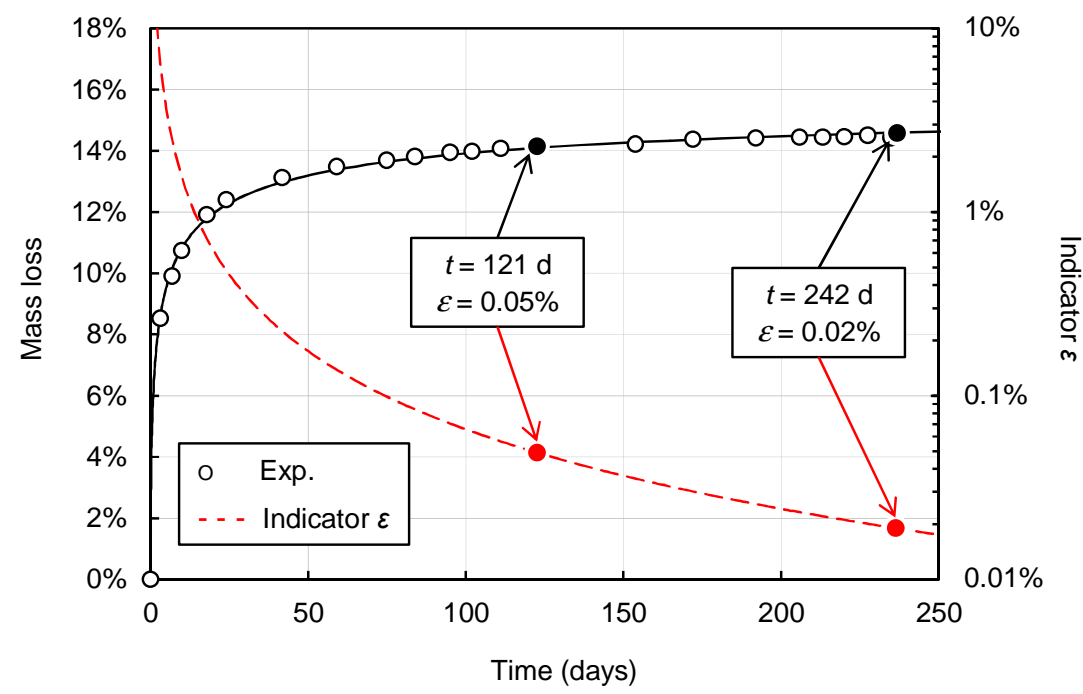

Figure 1. Illustration of the criterion $\varepsilon \leq 0.05 \%$ for the CEM I paste kept at $80^{\circ} \mathrm{C}$ and $76 \% \mathrm{RH}$ (in this example $A=-16.04 \%$ and $\left.B=1.522 d^{0.5}\right)$. Note the log-scale for the indicator $\varepsilon$.

Once the equilibrium was reached for all the sets of specimens (that is to say when $\varepsilon$ was lower than 
porosity $\emptyset$ ) and the relative mass variations at equilibrium. It was found convenient to describe the

283 pastes saturation state using the water content $w$ which is defined as the ratio of water to dry solid by

284 mass. In our case it could be easily calculated using the following equation:

$$
w(T, h)=\frac{d_{s}}{d_{s}-\emptyset}\left[\frac{\emptyset}{d_{s}}+\left(\frac{\Delta m}{m}\right)(T, h)\right]
$$

286 where $\left(\frac{\Delta m}{m}\right)(T, h)$ is the relative mass variation at equilibrium with the relative $h$ for the temperature $T$.

To ensure comparison between the desorption isotherm for the three temperatures a common reference dry state is necessary because temperature affects the free water amount. For instance drying at $20^{\circ} \mathrm{C}$ using silica gel $(\mathrm{RH}=3 \%)$ as proposed by Baroghel-Bouny $[19,56]$ is unsuitable here. It is known that heating at $80^{\circ} \mathrm{C}$ is harmful for cementitious materials mineralogy and microstructure [57-60]. Yet as far as only the first desorption is concerned (no preliminary drying and no further resaturation) drying at $80^{\circ} \mathrm{C}$ (using $\mathrm{CaCl}_{2}$ ) was chosen here for commodity. In so doing, it was implicitly assumed that the $80^{\circ} \mathrm{C}$-induced degradation influence on total porosity could be neglected. The authors acknowledge that drying at $80^{\circ} \mathrm{C}$ is not the common procedure. The reader should remind that porosity was also measured using different protocols (Table 8) and it is possible to use eq. (18) to recalculate the desorption isotherms (for instance $105^{\circ} \mathrm{C}$ ).

Two different models were used to fit the desorption isotherms: Mualem-van Genuchten equation (eq. 8) was used for unsaturated water transport and Pickett's model was used for adsorption physics. The model proposed by Pickett is considered by the authors to be the only simple model describing the physics of adsorption that can efficiently fit the results (type IV isotherms). Using a model based on adsorption physics instead of that of van Genuchten also proved to ensure a better estimation of the water content at $20 \%$ and isosteric energy $q_{s t}$. Pickett's equation is an evolution of the well-known BET model. It can be written under the following form: 
305

where:

- $\quad C^{P}$ is a positive constant that is related to the energy of adsorption of the first layer;

- $\quad w_{m}^{P}$ the monolayer value corresponds to the water content that is needed to complete a monomolecular layer;

- $n$ represents the maximal number of adsorbed layers;

- $\quad b$ is related to the rate of evaporation/condensation of water molecules in the layers.

\subsection{Permeability assessment}

We did not measure directly the intrinsic permeability $K\left(\mathrm{~m}^{2}\right)$, for instance using water permeametry [61] because such results are known to be unsuitable for the simulation of unsaturated water flow in concretes [22]. The intrinsic permeability was rather evaluated through inverse analysis as already proposed [20, 21]. For this purpose, the biggest cylinders $(\varnothing 51 \times \mathrm{H} 60 \mathrm{~mm})$ were put in climatic chambers using the constant environmental conditions reported in Table 5. Periodically the chambers were opened and the samples weighed. The tests were conducted for 65 days for $20^{\circ} \mathrm{C}$ and 14 days for 50 and $80^{\circ} \mathrm{C}$ respectively.

Table 5. Tests conditions for intrinsic permeability assessment tests.

\begin{tabular}{ccccc}
\hline Temperature & $20^{\circ} \mathrm{C}$ & $50^{\circ} \mathrm{C}$ & $80^{\circ} \mathrm{C}$ & Unit \\
\hline $\mathrm{RH}$ & $54 \%$ & $85 \%$ & $85 \%$ & - \\
Liquid pressure (eq. 4) & -83.29 & -23.96 & -25.78 & $\mathrm{MPa}$ \\
Duration & 65 & 14 & 14 & days \\
\hline
\end{tabular}


322 The experimental mass variations were then described using the simplified approach detailed in part 2.

323 From a practical point of view, the finite-element code Cast $3 \mathrm{~m}^{1}$ was used to solve eq. (7) and compute

324 the resulting theoretical mass variation. Different intrinsic permeability values were used and the best

325 value was selected using a least-squares minimization process. For more detail about the fitting process

326 the reader is referred to [23]. A quarter of the specimen was described in axisymmetric conditions

327 (Figure 2). 7200 four-node quadrangles $(80 \times 90)$ were used. The time steps were adjusted to ensure

328 convergence (from a few seconds at the beginning of the simulations to one day at the end).

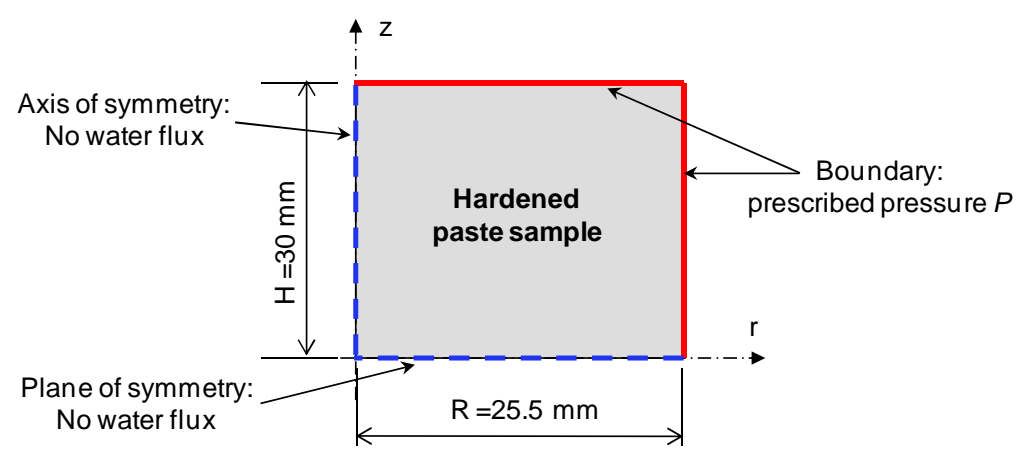

Figure 2. Schematic description of the numerical simulations for permeability assessment.

333 The heating stage was not described (the temperature was assumed to be constant). The initial

334 conditions were: uniform temperature $\left(20,50\right.$ or $80^{\circ} \mathrm{C}$ ) and liquid pressure $P=0.0 \mathrm{MPa}$ (saturation). At

$335 t=0$, a constant pressure (Dirichlet condition) was prescribed all over the sample boundary (the

336 corresponding values are listed in Table 5).

\footnotetext{
${ }^{1}$ http://www.cast3m.org
} 


\section{Results}

\subsection{Feedback on the use of saturated salt solutions}

339 Two major drawbacks were encountered when using saturated salt solutions. First, we did not find this method to be successful for $\mathrm{RH}$ regulation: a good illustration is given on Figure 3 . We prepared a sodium carbonate $\left(\mathrm{Na}_{2} \mathrm{CO}_{3}\right)$ solution in a four-liter desiccator (the same kind as the ones used for the water retention curve characterization) and left it four days in an oven at $80 \pm 1^{\circ} \mathrm{C}$. Temperature and $\mathrm{RH}$ were constantly recorded using a commercial hygrometer: the $\mathrm{RH}$ target (85\%, Table 4) was quickly reached. After four days, we opened the desiccator and introduced four (saturated) paste specimens. The RH within the desiccator then quickly increased to reach saturation (100\%) due to the water release by the four specimens. The RH only began to decrease 11 days after the samples introduction and returned to the target value 14 days after.

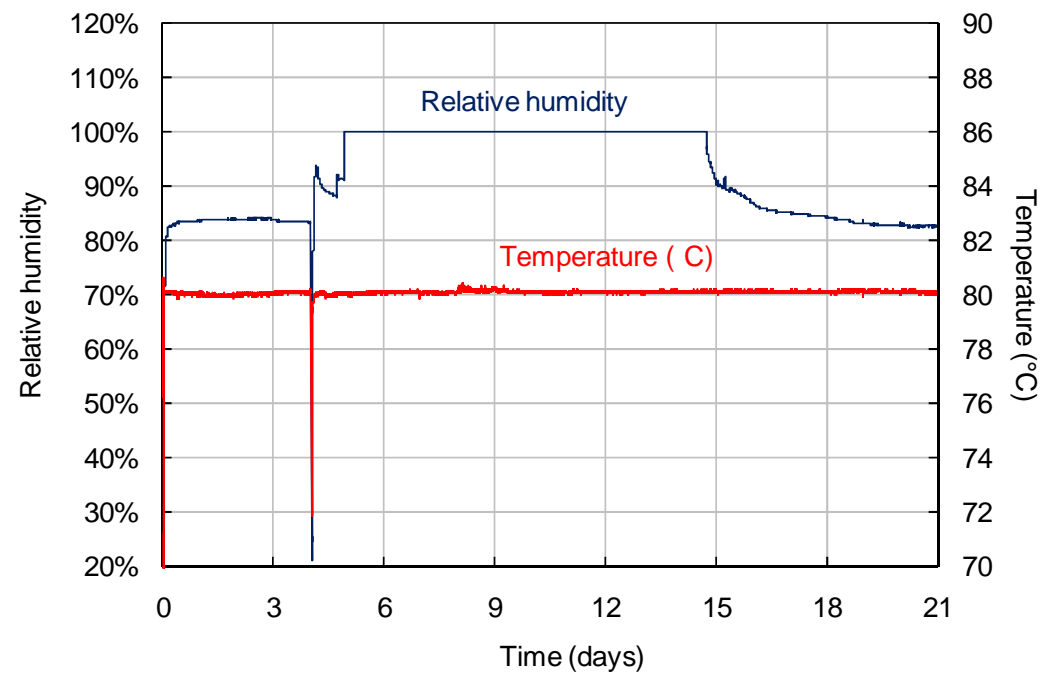

Figure 3. $\mathrm{RH}$ and temperature evolution within a desiccator after the insertion of four paste samples (the salt used is $\mathrm{Na}_{2} \mathrm{CO}_{3}$ resulting in $\mathrm{RH}=85 \%$ at $80^{\circ} \mathrm{C}$ ). 
353 In this example, only four specimens were introduced whereas sixteen of them were used in the water

354 retention curve experiments. In so doing, we did not expect the salt solutions to successfully maintain

355 the $\mathrm{RH}$ in the short term for the three tested temperatures. We believe that it did result in increasing the

356 time needed to reach equilibrium: the resulting mass loss evolutions of the specimens could not be used

357 for water transport properties evaluation. This explains why supplementary isothermal drying tests were

358 conducted for permeability assessment. In a more general way, when using saturated salt solutions to

359 maintain constant conditions one should at least monitor the RH evolution or if possible adjust the

360 chamber volume to the specimens water release rate and salt used.

361 The second major problem we had to face was the crystallization of salt above the solution on the

362 desiccator walls which could eventually come in contact with the specimens and result in unacceptable

363 pollution. This was believed (but it was not verified) to be due to the handling operations needed to have

364 the samples weighed (periodical withdrawal from the oven which could project some solution on the

365 desiccator walls) and to the supersaturation induced by the solution cooling and drying (due to the

366 desiccator opening). This was hindered by periodical examination (twice a week) of all the desiccators to

367 check the salt crystallization. When present, the desiccator walls were thoroughly rinsed and dried using

368 pure water and a clean towel. When the time between two remediation operations was too small, both

369 desiccator and salt solution were eventually changed. The salts under discussion are sodium bromide

$370(\mathrm{NaBr})$ which was found to be difficult to use at 50 and $80^{\circ} \mathrm{C}$ whereas sodium chloride $(\mathrm{NaCl})$, potassium

371 chloride $(\mathrm{KCl})$ and to a lesser extent magnesium chloride $\left(\mathrm{MgCl}_{2}\right)$ were only troublemaking at $80^{\circ} \mathrm{C}$.

372 4.2. Mineralogical composition

373 The contents of portlandite and C-S-H of each paste are presented on Table 6. The CEM I and CEM II

374 pastes showed pretty similar results (despite the limestone filler substitution). As expected, the Low-pH 


\begin{tabular}{cccccc}
\hline Phase & CEM I & CEM II & CEM V & Low-pH & Unit \\
\hline Portlandite & 5.6 & 5.4 & 2.1 & 0.0 & $\mathrm{~mol} / \mathrm{L}$ of paste \\
C-S-H & 5.1 & 5.0 & 7.0 & 7.4 & $\mathrm{~mol} / \mathrm{L}$ of paste \\
\hline
\end{tabular}

Table 6. Portlandite and C-S-H contents of the pastes after the cure.

A few TGA tests were also conducted using some of the specimens kept at $80^{\circ} \mathrm{C}\left(\right.$ and $\mathrm{CaCl}_{2}$ ) for the desorption isotherm characterization. The portlandite content of the CEM I paste was found to be almost constant versus $\mathrm{RH}$ whereas that of the CEM V paste decreased when RH was increased. This was taken as an indication of ongoing hydration (due to pozzolanic reactions) in the case of the blended cements (CEM V and Low-pH). We believe that this might have had an impact on the resulting water retention curves (especially at high $\mathrm{RH}$ and temperature) but we were unable to quantify it.

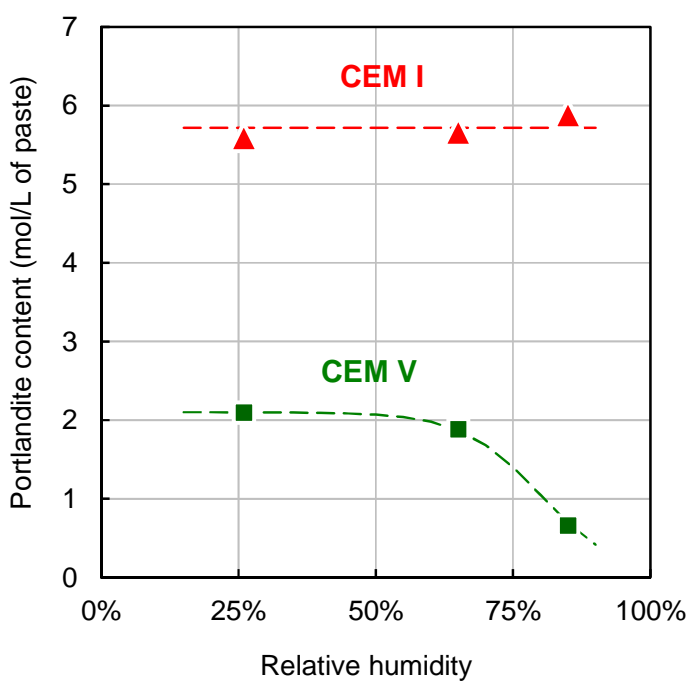

Figure 4. Portlandite content of the CEM I and CEM V pastes kept at $80^{\circ} \mathrm{C}$ (dashed lines are guides for the eye only). 


\subsection{Porosity and microstructure}

390

391

392

393

394

395

396

397

398

399

400

\begin{tabular}{ccccccc}
\hline Temperature & Desiccant & RH & CEM I & CEM II & CEM V & Low-pH \\
\hline $20^{\circ} \mathrm{C}$ & $\mathrm{SiO}_{2}$ & $\approx 3 \%$ & $30.4 \%$ & $31.0 \%$ & $28.5 \%$ & $32.1 \%$ \\
$50^{\circ} \mathrm{C}$ & $\mathrm{SiO}_{2}$ & $\approx 3 \%$ & $35.2 \%$ & $35.9 \%$ & $34.2 \%$ & $40.3 \%$ \\
$80^{\circ} \mathrm{C}$ & $\mathrm{CaCl}_{2}$ & $\approx 0 \%$ & $37.2 \%$ & $39.5 \%$ & $38.9 \%$ & $41.3 \%$ \\
$105^{\circ} \mathrm{C}$ & - & - & $38.5 \%$ & $40.4 \%$ & $39.1 \%$ & $45.7 \%$ \\
\hline
\end{tabular}

401

402

\begin{tabular}{ccccc}
\hline Paste & CEM I & CEM II & CEM V & Low-pH \\
\hline Saturated specific gravity $d_{\text {sat }}$ & $2.04(0.01)$ & $1.99(0.01)$ & $1.93(0.01)$ & $1.73(0.01)$ \\
\hline
\end{tabular}

Table 8. Porosity as a function of drying temperature.

Table 7. Specific gravity of the pastes (standard deviation in brackets). 
The MIP results are presented on Figure 5. The CEM I \& CEM II pastes exhibited almost the same pore-

405 size distribution. The CEM V and Low-pH pore-size distributions showed an important reduction of the 406 pores of diameter larger than $50 \mathrm{~nm}$ (despite the presence of an unexpected and unexplained pore 407 population around $200 \mathrm{~nm}$ for the CEM V) together with an important increase of pores of diameter 408 lower than $50 \mathrm{~nm}$. This was attributed to the presence of SCMs in the CEM V and Low-pH mix leading to 409 supplementary C-S-H formation (see Table 6).

410
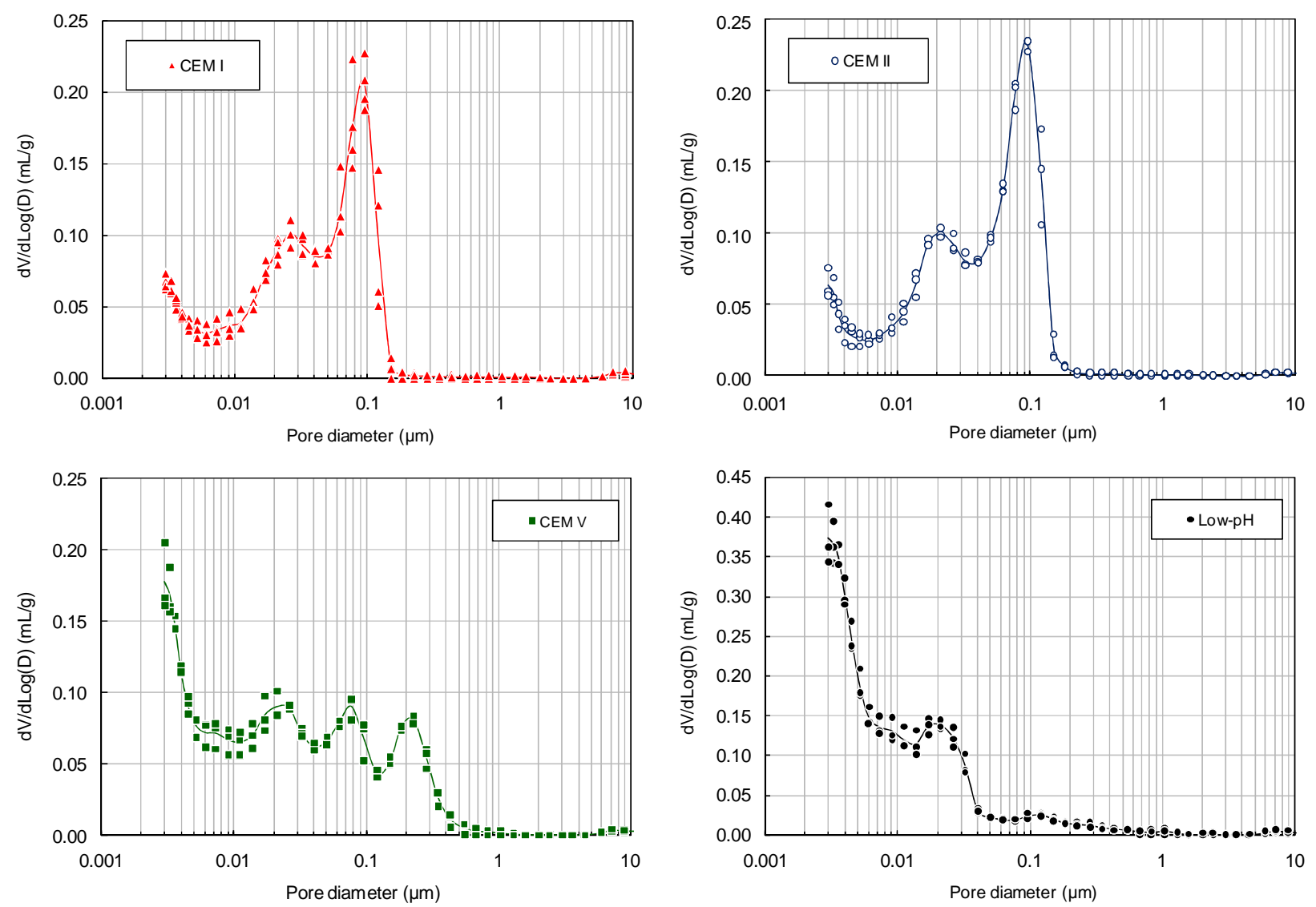

411 Figure 5. Pore-size distribution of the four hardened cement pastes as obtained using MIP and samples 
414 The MIP results obtained using heated specimens are depicted on Figure 6 . Whatever the considered

415 paste, heating led to the coarsening of the pore structure: that is to say the increase of both capillary

416 porosity and critical pore radius (corresponding to the sudden slope change in the MIP results). As

417 suggested by Brue et al. [14] ettringite dissolution [62, 63] as well as C-S-H alteration [64-66] can be 418 considered as the major causes of the pore structure modifications.

419
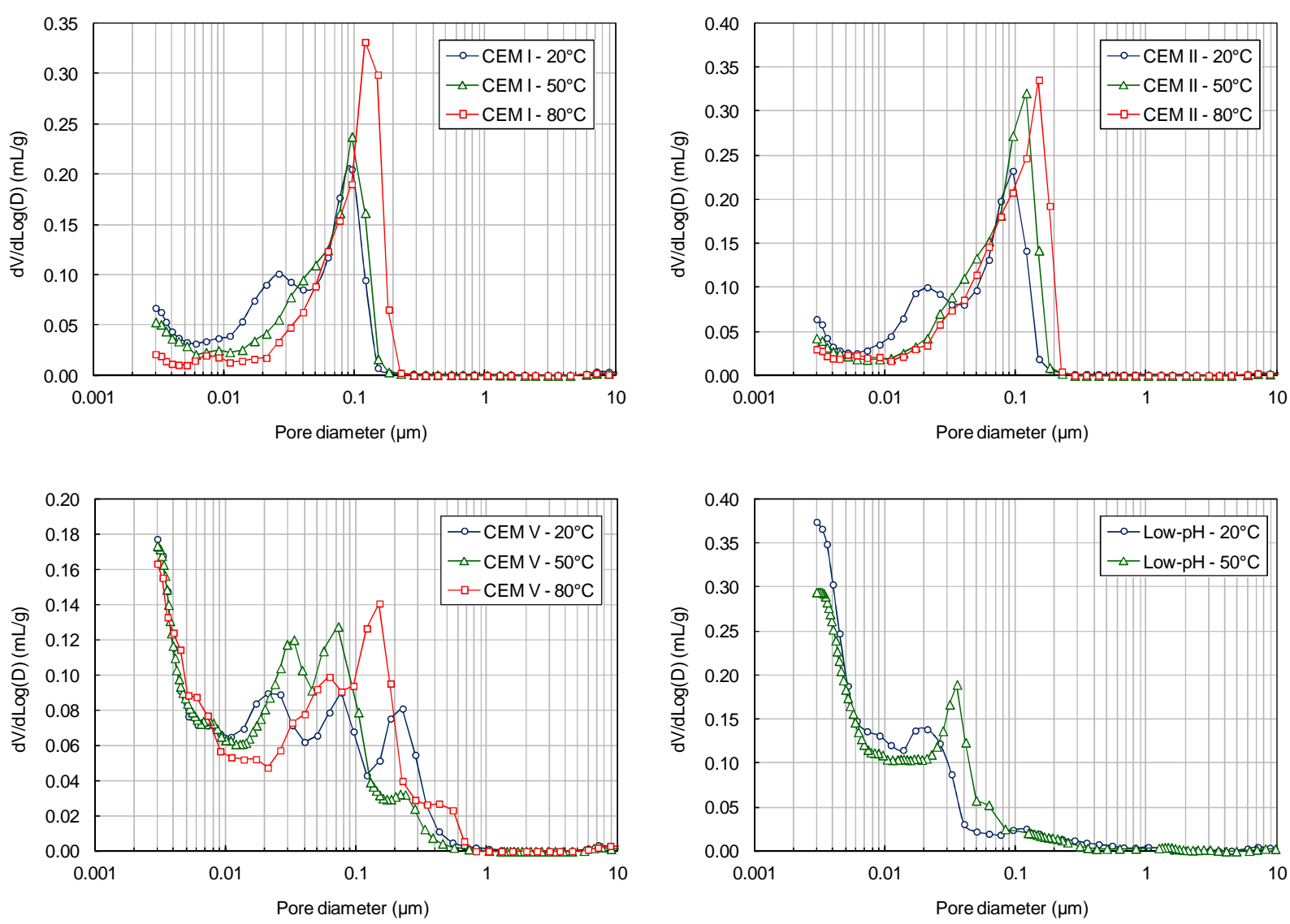

420 Figure 6. Pore size distribution versus temperature as obtained using MIP. Each curve corresponds to the

421 mean result of 3 or 4 tests. It was not possible to obtain reliable and repeatable results for the Low-pH samples kept at $80^{\circ} \mathrm{C}$ : these results are not presented. 


\subsection{Desorption isotherms}

424 The first desorption isotherm at $20^{\circ} \mathrm{C}$ of the four pastes are presented on Figure 7 . The depicted curves

425 are of type IV according to the classification originally proposed by Brunauer $[46,67]$ : one can note the monomolecular layer edification at low RH as well as the presence of a plateau near saturation (at least for CEMV and Low-pH) representative of capillary condensation within a meso-porous medium.

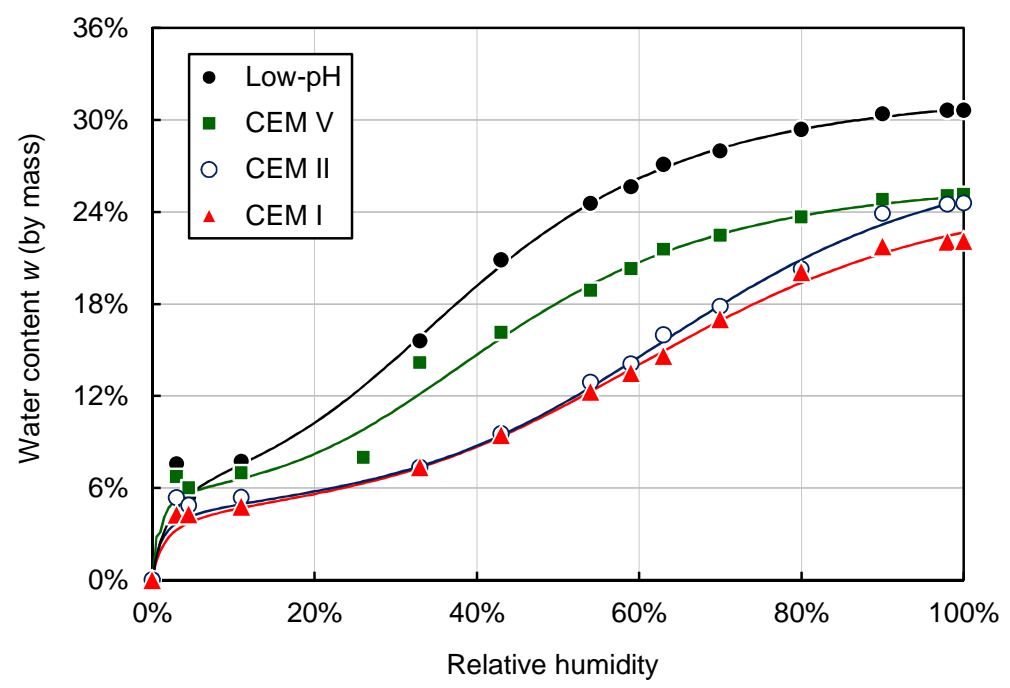

Figure 7. First desorption isotherm at $20^{\circ} \mathrm{C}$ for the four pastes. Each symbol corresponds to the mean value of each sample set (at least three samples) whereas the solid lines (Pickett's model) are just guides for the eye.

Similarly to the MIP results, the CEM I and CEM II pastes exhibit almost the same desorption curve despite the $25 \%$ clinker-substitution by carbonate filler. The two curves differ at high RH: the CEM II

435 paste retains more water at saturation than the CEM I due to higher porosity. This isotherm shape is very

436 similar to the ones obtained using ordinary cementitious materials (pastes and concretes, w/c from 0.35

437 to 0.45 ) by Baroghel-Bouny [56]. The CEM V and Low-pH pastes show a different general pattern. The 
438 presence of a plateau near saturation $(\mathrm{RH}=100 \%)$ is much more noticeable than for CEM I \& II: the

439 desorption isotherm slope at high $\mathrm{RH}$ is lower than the ones of CEM I \& II (due to a refined pore size

440 distribution). The water content at low RH (typically for monomolecular adsorption) is also higher than

441 for CEM I \& II due to higher C-S-H content.

442 The impact of temperature on the water retention curve is depicted on Figure 8. Whatever the

443 considered paste a temperature increase induces the reduction of the water retained at equilibrium with

444 any arbitrary $\mathrm{RH}$. This effect was observed over the whole $\mathrm{RH}$-range and even at $\mathrm{RH}=100 \%$ for the CEM I

445 and CEM II pastes but was hardly observed for the CEM V and Low-pH pastes. This was attributed to the

446 effect of ongoing hydration as detected using TGA: the resulting mass gain helped reduce the fall in

447 water content at high RH.
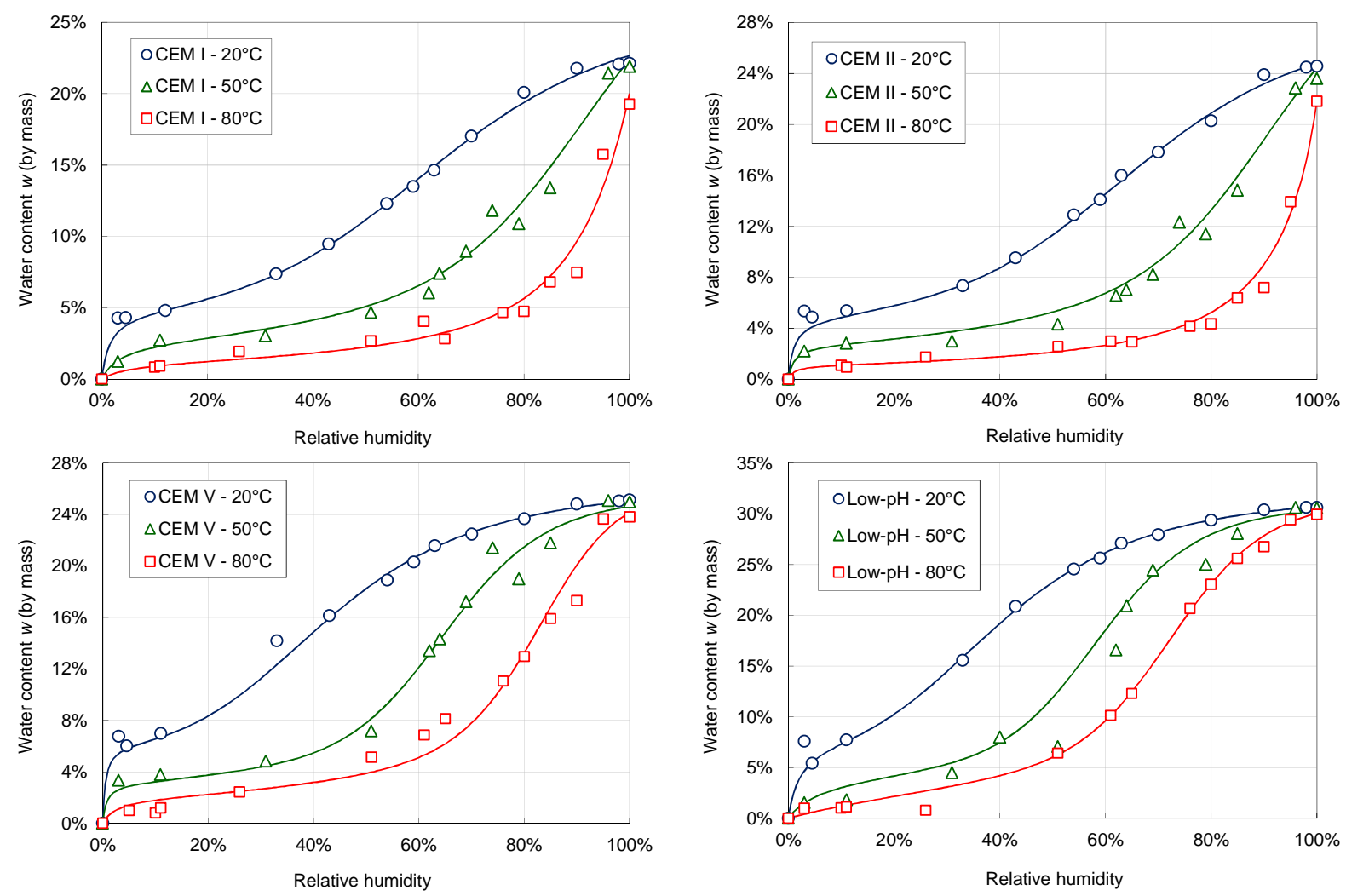
Figure 8. Desorption isotherm of the four hardened pastes as a function of temperature (water content). Each symbol corresponds to the mean value of each sample set (at least three samples) whereas the solid lines stand for the interpolation using Pickett's model.

\subsection{Isoteric energy}

The isosteric energy of adsorption $q_{s t}$ was assessed using eq. (1). The RH $h$ at equilibrium with the water content $w$ was evaluated using Pickett's model (eq. 18) and the vapor pressure $p_{v}$ was calculated using Rankine's equation:

$$
p_{v}(w, T)=h(w, T) p_{v s}(T)=h(w, T) P_{a} \exp \left(\alpha-\frac{\beta}{T}\right)
$$

with $P_{a}=101325 \mathrm{~Pa} ; \alpha=13.7$ and $\beta=5120 \mathrm{~K}$. The function used to interpolate $p_{v s}(T)$ is of first importance because it appeared to influence the results obtained (the evolution remains unchanged but the values are modified). The resulting isosteric energy evolutions are plotted on Figure 9 as functions of coverage $\frac{w}{w_{m}}$ (number of adsorbed layers). This presentation allows the results to be fully comparable (and not to depend on density and porosity). Apart from the Low-pH mix all the curves exhibit the same evolution: $q_{s t}$ increases at low coverage (typically between 0.0 and 0.5 ) from $70 \mathrm{~kJ} / \mathrm{mol}$ to reach a maximal value (around $100 \mathrm{~kJ} / \mathrm{mol}$ ) and then continuously decreases to get close to the average water enthalpy of condensation $\left(43.7 \mathrm{~kJ} / \mathrm{mol}\right.$ between 20 and $\left.80^{\circ} \mathrm{C}\right)$ at high coverage. Note that the uncertainty related to the maximal isosteric evaluation process was estimated to $\pm 10 \mathrm{~kJ} / \mathrm{mol}$. 
466

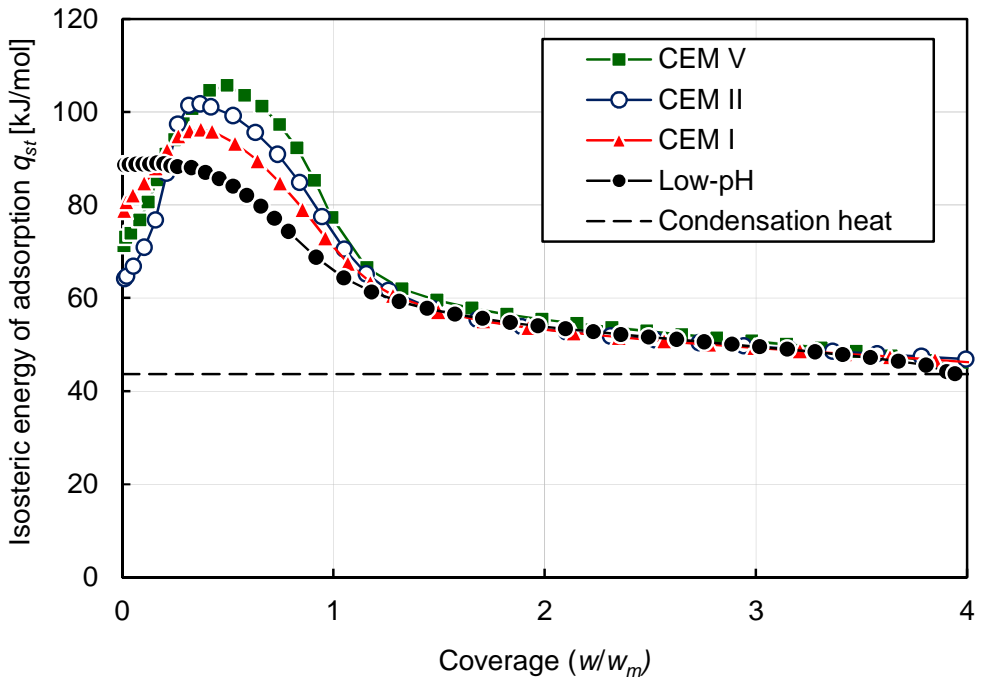

Figure 9. Isosteric energy of adsorption $q_{s t}$ of the four considered hardened cement pastes.

Most of $q_{s t}$ variations can be observed in the first layer (that is to say for $w / w_{m}$ less than 1.0 ) which is representative of the strong interaction between the first water layer and the hardened cement paste.

The $q_{s t}$ decrease (for $w / w_{m}$ greater than 0.5 ) is representative of the decrease of the cementitious material influence with the increase of the distance between the newly adsorbed water molecules and substrate. The asymptotic value for high coverage $(43.7 \mathrm{~kJ} / \mathrm{mol})$ corresponds to the average water condensation energy (between 20 and $80^{\circ} \mathrm{C}$ ): it can be considered that there is no more influence of the cementitious material substrate and all water molecules are bonded the ones to the others (liquid state representative of capillary condensation).

An increase in $q_{s t}$ in the first layer is not common: monotonic decrease is generally observed. In our case, the maximum might just be due to the isosteric energy estimation process (use of Pickett's model rather than another arbitrary function for instance) and to the lack (and variability) of the experimental results in the monolayer zone (between 0 and 30\% RH). Yet a maximum has already been observed for different 
materials [68-76]. For hydrophobic materials such as activated carbons $[70,71] q_{s t}$ increases from low

482 values at low coverage (due to the lack of hydrophilic sites) up to the condensation enthalpy in relation

483 to the formation of water clusters. For hydrophilic materials the increase is usually explained by the

484 swelling of the dry matrix resulting in the exposure of new adsorption sites of high binding energy. When

485 all the high energy sites are occupied water adsorption occurs on less energetic sites leading to the $q_{s t}$

486 decrease. In the case of cementitious materials, the $q_{s t}$ increase might be due to the desaturation and

487 the subsequent collapse of the C-S-H interlayer space $[77,78]$ preventing water access to high-binding

488 energy adsorption sites within the C-S-H interlayer. This simple assumption would deserve additional

489 experiments to be confirmed (or infirmed).

490 Figure 10 presents the comparison between the isosteric energy obtained in this study (open circles) for

491 the CEM I paste and the corresponding concrete (filled circles) [13, 17]. It is obvious that the two

492 evolutions do not match: the maximal value obtained for the concrete is about $66 \mathrm{~kJ} / \mathrm{mol}$ whereas it

493 reaches $100 \mathrm{~kJ} / \mathrm{mol}$ for the paste. One could then conclude that there is no consistency between these

494 two results. As a matter of fact, two different models were used to describe the desorption isotherm in

495 both cases: GAB and Pickett models for the concrete and the paste respectively. These models were used

496 to calculate the $\mathrm{RH}$ (and then the vapor pressure) at equilibrium with any arbitrary water content as

497 needed for Clausius-Clapeyron equation, see [17] for more details. When we used Pickett's model to

498 evaluate the concrete isosteric energy from the CEM I paste results we obtained an almost perfect

499 match. The equation used for the description of the water retention curve (GAB or Pickett in our case)

500 appears to be very important since it greatly influences the resulting isosteric energy $q_{s t}$. As a

501 consequence when handling such data, one has to be very careful and be consistent in the choice of the

502 model used to describe the water retention curve in order to avoid erroneous results. 


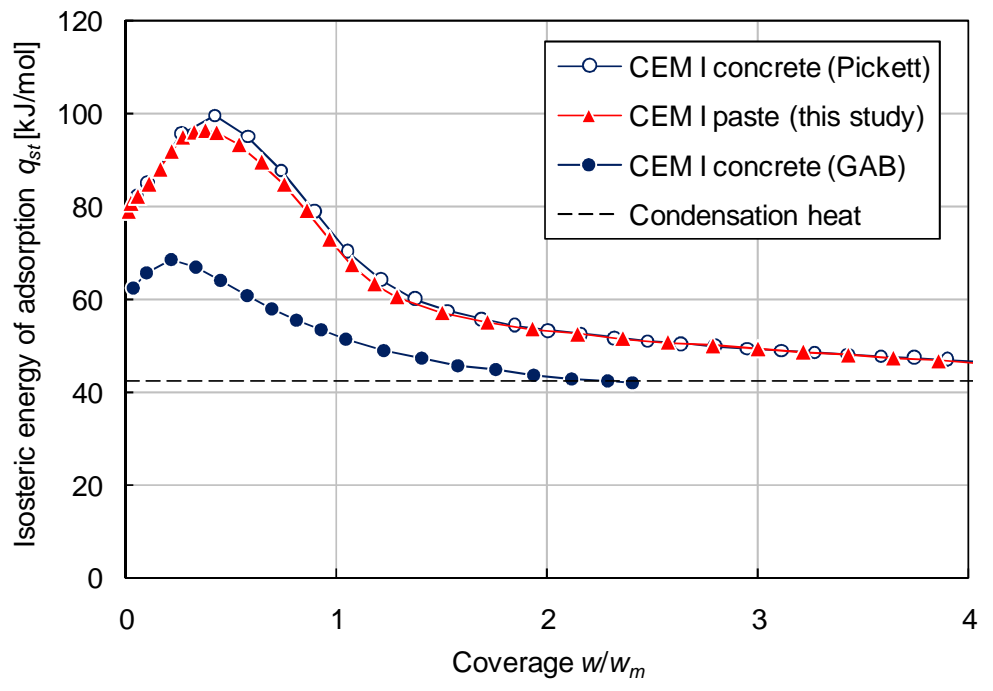

Figure 10. Comparison between the isosteric energy evolutions obtained in this study and in a previous study $[13,17]$.

This good isosteric energy correspondence was also supported by the comparison between paste and concrete desorption isotherm as shown in Figure 11. Figure 11 (a) presents the experimental desorption isotherm at $80^{\circ} \mathrm{C}$ for the CEM I paste tested in this study and the corresponding concrete studied in [13].

510 To make the two isotherms comparable (porosity and density are different) the water content $w$ was

511 divided by its maximal value $w_{\max }$. The two datasets describe almost the same curve (despite the

512 variability). Figure 11 (b) presents the comparison between the CEM I concrete desorption isotherm

513 acquired at $30^{\circ} \mathrm{C}$ and the CEM I paste curve estimated using Clausius-Clapeyron and Pickett's model and 514 the corresponding isosteric energy $q_{s t}$ (Figure 10). Once again, the comparison is very good. It is known 515 that for high-performance materials the presence of aggregates does not influence the water retention 516 curve $[55,56]$ : these results also show that it does not influence the isosteric energy (that is to say the 517 variation induced by temperature). 


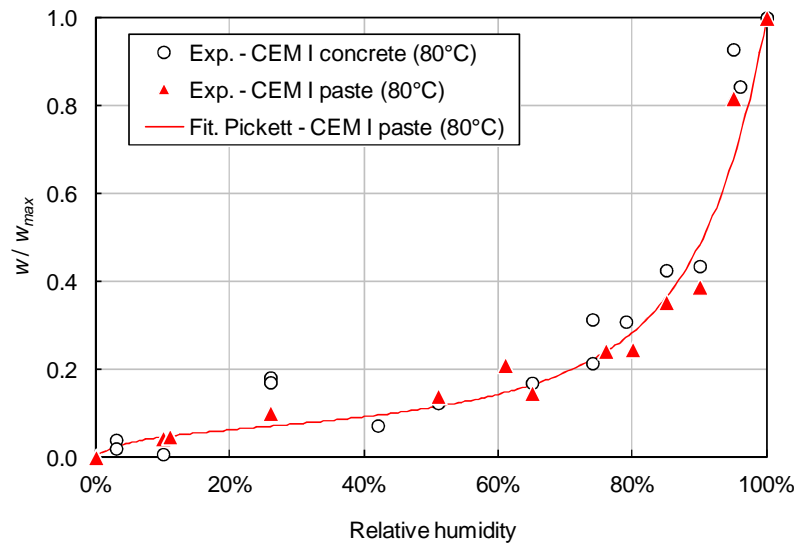

(a) Desorption isotherms at $80^{\circ} \mathrm{C}$ (CEM I paste and corresponding concrete)

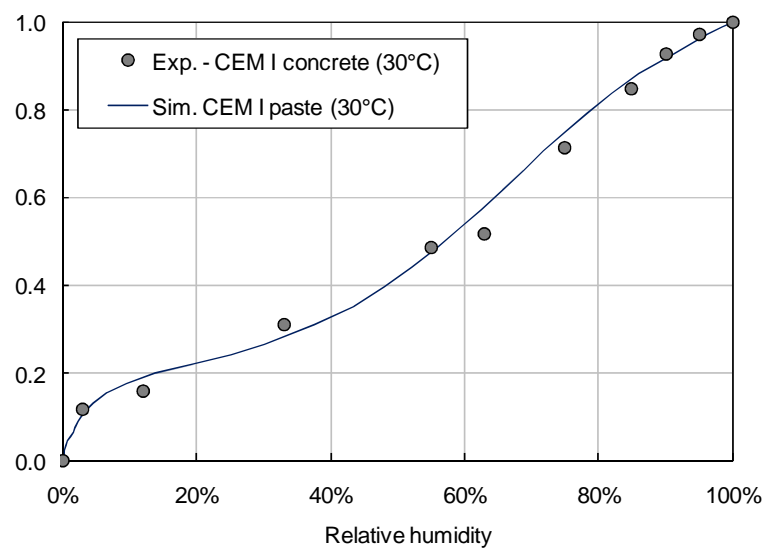

(b) Desorption isotherm at $30^{\circ} \mathrm{C}$

Figure 11. Comparison between the desorption isotherms of the CEM I paste tested in this study and the corresponding concrete [13].

\subsection{Water transport}

Figure 12 presents the experimental mass loss evolution of the samples dried at $20^{\circ} \mathrm{C}$ and $54 \% \mathrm{RH}$ (the

523 initial mass of the saturated specimens was taken as reference/standard to compute mass loss). The CEM II paste exhibited the fastest mass loss ( $7 \%$ after 60 days) far above the CEM I (4.5\% after 60 days). Here the effect of the $25 \%$ clinker substitution by limestone filler appeared to have a significant impact

526 (unlike the pore-network distribution and desorption isotherm). The CEM V and Low-pH pastes showed 527 almost the same mass loss evolution (3.3\% after 60 days). 


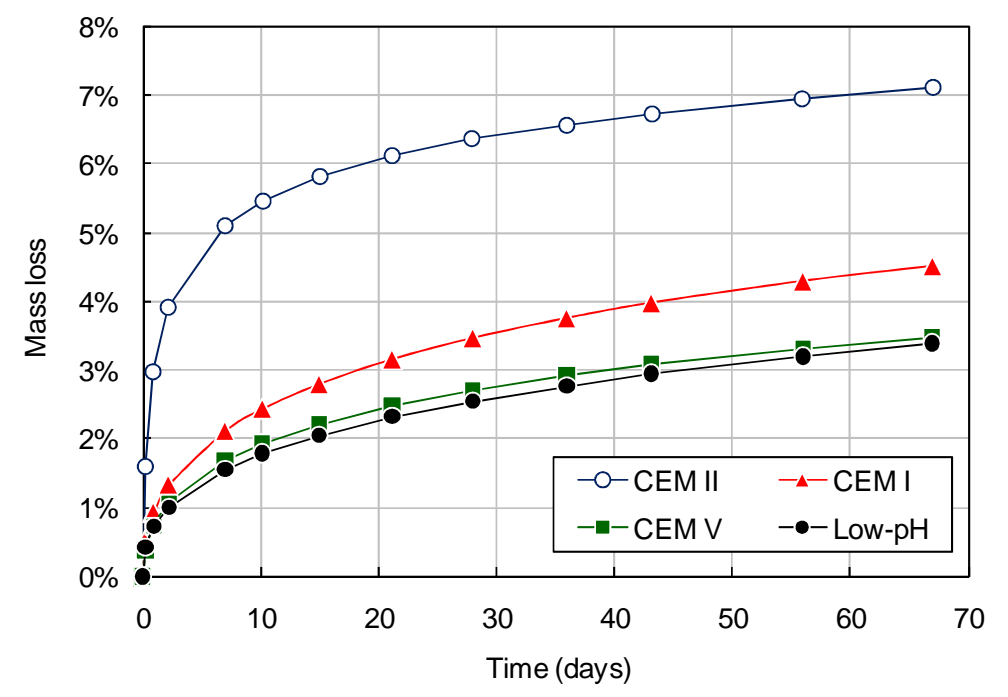

Figure 12. Experimental mass loss of the paste samples dried at $20^{\circ} \mathrm{C}$ and $54 \% \mathrm{RH}$.

530 The two van Genuchten's parameters $P_{0}$ and $m$ needed in eq. (8) were fitted on the experimental

531 desorption isotherms (Figure 13): the corresponding values are reported in Table 10 . At $20^{\circ} \mathrm{C}$ the values

532 obtained are consistent with the literature $[19,22,28]$. It is noteworthy that when temperature

533 increases the $m$ values remain stable whereas those of $P_{0}$ decrease. The relative permeability evolutions

534 at $20^{\circ} \mathrm{C}$ are depicted on Figure 14 (a). As expected the finer the pore size distribution, the lower the

535 relative permeability decrease with saturation. The relative permeability evolutions can be classified in

536 the following order: Low-pH > CEM V > CEM I > CEM II. 

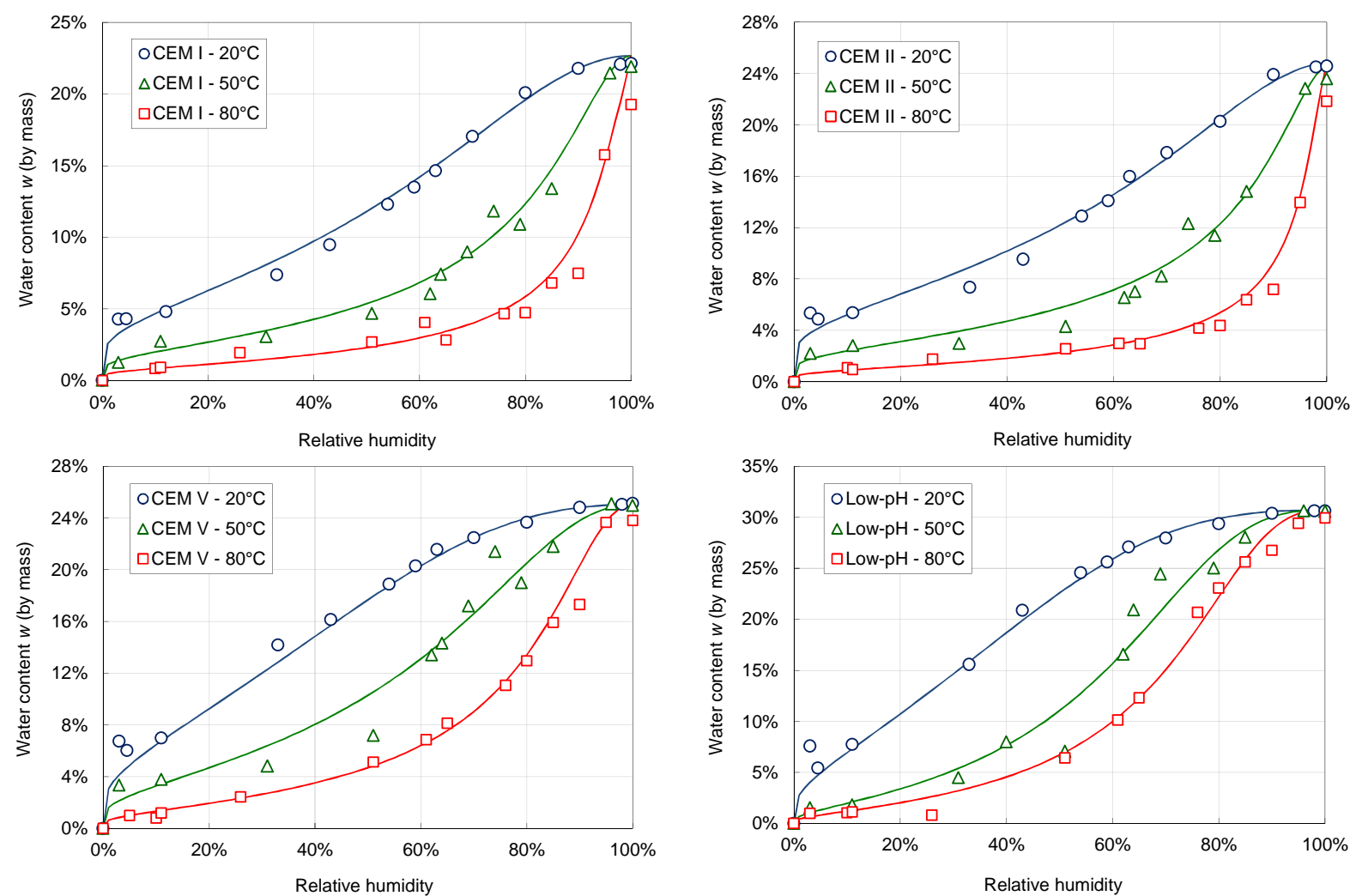

Figure 13. Desorption isotherm of the four hardened pastes as a function of temperature (saturation)

Table 10. Van Genuchten parameters and permeability values.

\begin{tabular}{ccccccc}
\hline \multicolumn{2}{c}{ Paste } & CEM I & CEM II & CEM V & Low-pH & Unit \\
\hline \multirow{2}{*}{$20^{\circ} \mathrm{C}$} & $P_{0}$ & 51.4 & 42.5 & 96.9 & 108.7 & $\mathrm{MPa}$ \\
& $m$ & 0.465 & 0.437 & 0.529 & 0.578 & - \\
& $K$ & $2.0 \times 10^{-22}$ & $8.0 \times 10^{-22}$ & $7.0 \times 10^{-23}$ & $2.5 \times 10^{-23}$ & $\mathrm{~m}^{2}$ \\
\hline \multirow{2}{*}{$50^{\circ} \mathrm{C}$} & $P_{0}$ & 18.9 & 14.7 & 47.1 & 56.8 & $\mathrm{MPa}$ \\
& $m$ & 0.457 & 0.425 & 0.506 & 0.605 & - \\
& $K$ & $3.0 \times 10^{-22}$ & $22.0 \times 10^{-22}$ & $3.0 \times 10^{-23}$ & $4.6 \times 10^{-23}$ & $\mathrm{~m}^{2}$ \\
\hline \multirow{2}{*}{$80^{\circ} \mathrm{C}$} & $P_{0}$ & 8.1 & 5.2 & 23.5 & 40.3 & $\mathrm{MPa}$ \\
& $m$ & 0.458 & 0.436 & 0.517 & 0.595 & - \\
& $K$ & $140.0 \times 10^{-22}$ & $600.0 \times 10^{-22}$ & $150.0 \times 10^{-23}$ & $18.0 \times 10^{-23}$ & $\mathrm{~m}^{2}$ \\
\hline
\end{tabular}




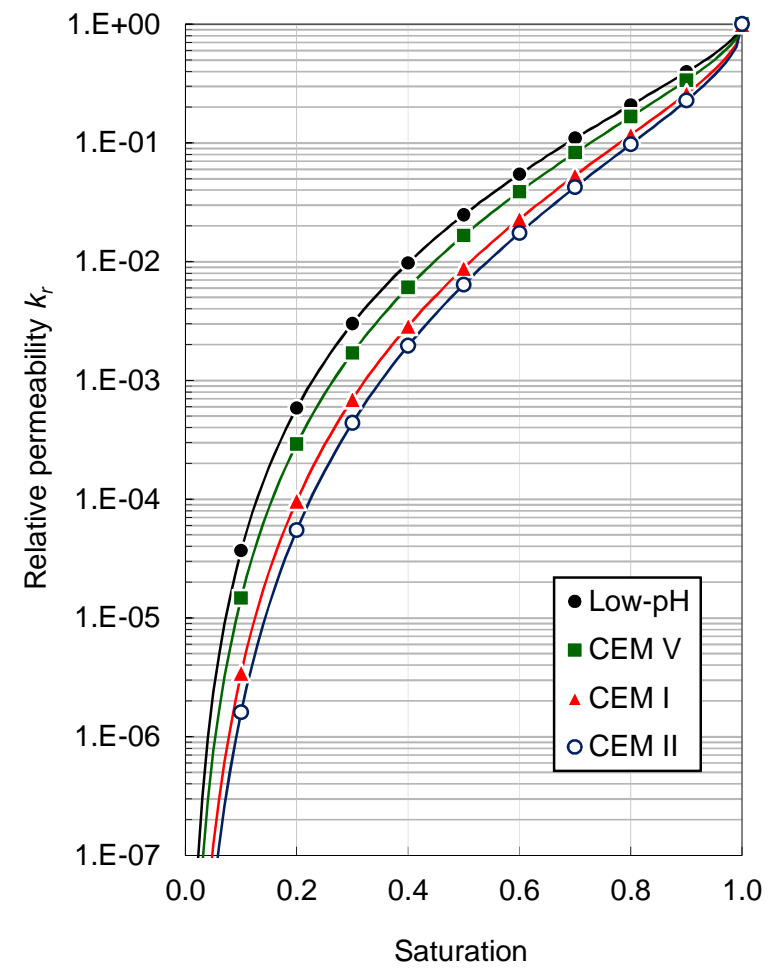

(a) Relative permeability $k_{r}$

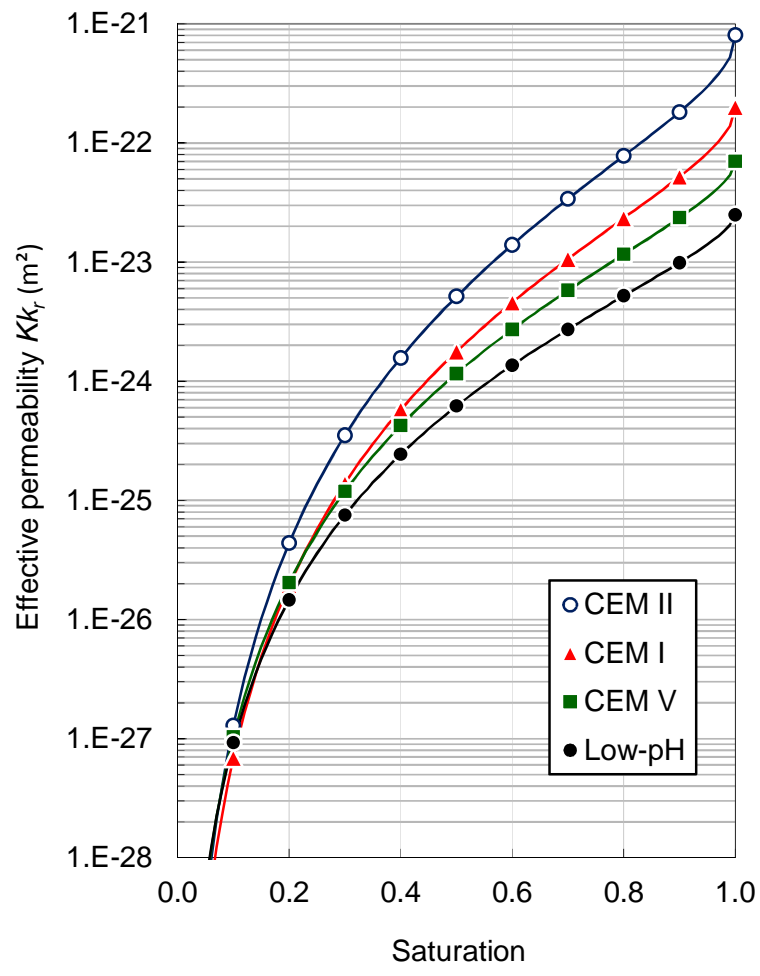

(b) Effective permeability $K k_{r}$

544 Table 10 recapitulates the intrinsic permeability values assessed using inverse analysis. At $20^{\circ} \mathrm{C}$ they can

545 be classified in the exact inverse order obtained for the relative permeability as shown in Figure 14 (b):

546 CEM II > CEM I > CEM V > Low-pH. This order is consistent with the pastes pore-network fineness as well

547 as the $\mathrm{C}-\mathrm{S}-\mathrm{H}$ content. Figure 15 presents the permeability variations induced by temperature. Unlike the

548 results of Powers [5], they could not be described the classical Arrhenius law (the points were not

549 aligned in the log-scale plot). For fitting purposes a double exponential law (eq. 20) was alternatively 550 proposed:

$$
K(T)=K_{0} \exp \left[\exp \left(\frac{T-293.15}{T_{c}}\right)-1\right]
$$


553 noted that the CEM V paste showed an unexpected and unexplained permeability decrease between 20

554 and $50{ }^{\circ} \mathrm{C}$ which cannot be described using eq. (18).

555

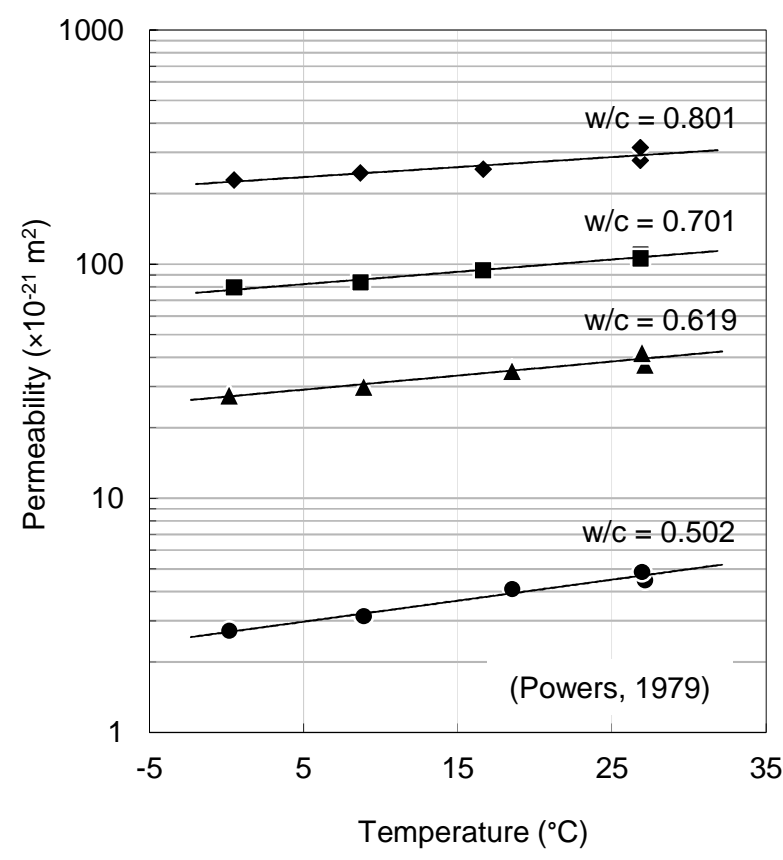

(a) Direct measurement from Powers (1979)

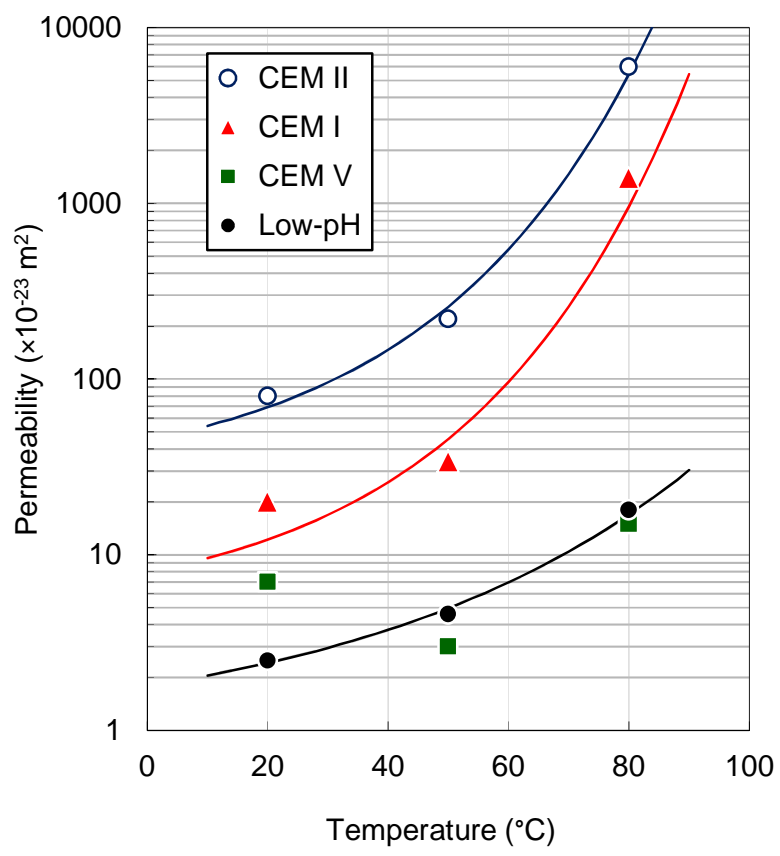

(b) Inverse analysis from this study

Figure 15. Permeability versus temperature: (a) following Powers [5], using water permeametry between 0 and $30^{\circ} \mathrm{C}$ and $(b)$ inverse analysis from this study. Table 11. Parameters for the description of temperature influence on permeability (eq. 20).

\begin{tabular}{cccccc}
\hline Parameter & CEM I & CEM II & CEM V & Low-pH & Unit \\
\hline$K_{0}$ & $12.2 \times 10^{-23}$ & $69.1 \times 10^{-23}$ & N/A & $2.4 \times 10^{-23}$ & $\mathrm{~m}^{2}$ \\
$T_{c}$ & 35.7 & 35.7 & N/A & 55.6 & $\mathrm{~K}$ \\
\hline
\end{tabular}




\section{Discussion}

560 The use of Clausius-Clapeyron to describe the water retention curve temperature induced modifications

561 implicitly assumes that the cementitious material pore structure remains unchanged. This assumption

562 was found to be acceptable for a high-performance concrete between 30 and $80^{\circ} \mathrm{C}$ [13]. The coarsening

563 of the pore structure observed using MIP in this study (from 20 to $80^{\circ} \mathrm{C}$ ) is supported by the permeability

564 results and the unsuccessful comparison with the results of Powers [5] (Figure 15). He showed that

565 between 0 and $30^{\circ} \mathrm{C}$ (temperature range within which no temperature induced modification of the pore

566 structure was expected) the permeability variations can be fitted by a classical Arrhenius law. In our case

567 the permeability variations are too big to be fitted by such a function. This is consistent with an increase

568 of the transport properties associated to porosity opening. There is however other potential causes of

569 the important permeability increase. Heating up to $80^{\circ} \mathrm{C}$ might have caused microcracking or increased

570 the contribution of water transport in the gaseous phase which is not accounted for in our simplified

571 approach. This might have resulted in overestimating the pastes permeability values at high

572 temperature.

573 The coarsening of the pore structure observed calls into question the use of Clausius-Clapeyron and the

574 corresponding assumption of unaltered microstructure. Indeed it is true that the pore structure coarsens

575 when temperature increases: the error induced by our assumption also increases with temperature.

576 Nevertheless, we believe that thermal desorption is the major mechanism at work for moderate

577 temperatures (let us state up to $50^{\circ} \mathrm{C}$ ). For temperatures up to $80^{\circ} \mathrm{C}$, alteration of the pore structure

578 might have a non-negligible impact on the water retention curve. Unfortunately there is nowadays no

579 way to quantify the link the pore structure determined using MIP and the water retention curve and

580 Clausius-Clapeyron remains the only available tool to describe the influence of temperature.

581 Consequently it is difficult to estimate the error associated to our assumption. In a simple way one could 
583 (from 20 to $80^{\circ} \mathrm{C}$ ) and analyze the results to evaluate the contribution of the microstructure variation.

\section{6. Conclusion}

Temperature has a great importance for water transport in cementitious materials. This issue is of first importance for the durability assessment of reinforced concrete structures for radioactive waste management. An experimental campaign was then designed to determine the influence of temperature on cementitious materials water transport properties. Four hardened cement pastes of interest for radioactive waste management were selected. Using a simplified approach, the transport of water was described using liquid permeation only. This allowed reducing the number of properties to acquire experimentally: porosity, water retention curve and (intrinsic and relative) permeability.

The water retention curve was characterized using the saturated salt solution method. The unsaturated permeability was assessed using inverse analysis making use of the Mualem-van Genuchten model.

594 Three temperatures were tested: 20,50 and $80^{\circ} \mathrm{C}$. As expected, temperature was found to have a great

595 impact on the water retention curve: a temperature increase decreased the water content at equilibrium

596 for all the pastes. The intrinsic permeability value significantly increased with temperature, but the data 597 obtained do not follow Arrhenius activation law. These results constitute a valuable and consistent data 598 set for the description of water transport in the field of radioactive waste management.

599 The temperature induced alteration of the water retention curves were described using Clausius-

600 Clapeyron equation and the corresponding isosteric energy of adsorption was evaluated. In so doing, the 601 microstructure was assumed not to be altered during the heating. The coarsening of the pore structure subsequent to heating was however highlighted using MIP. The water retention curve modifications 
603

604 605 606

were then assumed to result from a combination of thermal desorption (described by Clausius-Clapeyron equation) and pore structure coarsening. The influence of the latter remains to be evaluated.

\section{Acknowledgements}

This work was financially supported by the French agency for radioactive waste management (Andra).

\section{References}

[1] K. Tuutti, Corrosion of steel in concrete, Swedish Cement and Concrete Research Institute, 1982, pp. 468.

[2] B.P. Hughes, I.R.G. Lowe, J. Walker, The diffusion of water in concrete at temperatures between 50 and 95 ${ }^{\circ}$, British Journal of Applied Physics, 17 (1966) 1545-1452.

[3] N.L. Hancox, The role of moisture diffusion in the drying of cement paste under the influence of temperature gradients, Journal of Physics D: Applied Physics, 1 (1968) 1769-1777.

[4] G.M. Glover, E. Rassk, Water diffusion and microstructure of hardened cement pastes, Materials and Structures, 5 (1972) 315-322.

[5] T.C. Powers, The specific surface area of hydrated cement obtained from permeability data, Materials and Structures, 12 (1979) 159-168.

[6] J.-F. Daïan, Condensation and isothermal water transfer in cement mortar, part I - pore size distribution, equilibrium, water condensation and imbibition, Transport in Porous Media, 3 (1988) 563589.

[7] S.F. Wong, T.H. Wee, S. Swaddiwudhipong, S.L. Lee, Study of water movement in concrete, Magazine of Concrete Research, 53 (2001) 205-220.

[8] R. Černy, J. Drchalová, P. Rovnaníková, The effects of thermal load and frost cycles on the water transport in two high-performance concretes, Cement and Concrete Research, 31 (2001) 1129-1140. 
625 [9] M. Jooss, H.W. Reinhardt, Permeability and diffusivity of concrete as function of temperature,

626 Cement and Concrete Research, 32 (2002) 1497-1504.

627 [10] J. Hundt, H. Kantelberg, Sorptionsuntersuchungen an zemestein, zementmörtel und beton (in 628 german), Deutscher Ausschuss für Stahlbeton, Heft 297 (1978) 25-39.

629 [11] F. Radjy, E.J. Sellevold, K.K. Hansen, Isosteric vapor pressure-temperature data for water sorption in 630 hardened cement paste: enthalpy, entropy and sorption isotherms at different temperatures, Report 631 BYG-DTU R057, Technical University of Denmark (DTU), Lyngby, Denmark, 2003, pp. 58.

632 [12] T. Ishida, K. Maekawa, T. Kishi, Enhanced modeling of moisture equilibrium and transport in 633 cementitious materials under arbitrary temperature and relative humidity history, Cement and Concrete 634 Research, 37 (2007) 565-578.

635 [13] S. Poyet, Experimental investigation of the effect of temperature on the first desorption isotherm of 636 concrete, Cement and Concrete Research, 39 (2009) 1052-1059.

637 [14] F. Brue, C.A. Davy, F. Skoczylas, N. Burlion, Effect of temperature on the water retntion properties of 638 two high-performance concretes, Cement and Concrete Research, 42 (2012) 384-396.

639 [15] J. Jiang, Y. Yuan, Relationship of moisture content with temperature and relative humidity in 640 concrete, Magazine of Concrete Research, 65 (2013) 685-692.

641 [16] M. Wu, B. Johannesson, M. Geiker, A study of the water vapor sorption isotherms of hardened 642 cement pastes: possible pore structure changes at low relative humidity and the impact of temperature 643 on isotherms, Cement and Concrete Research, 56 (2014) 97-105.

644 [17] S. Poyet, S. Charles, Temperature dependence of the sorption isotherms of cement-based materials: 645 heat of sorption and Clausius-Clapeyron formula, Cement and Concrete Research, 39 (2009) 1060-1067. 646 [18] H. Pan, J.A. Ritter, P. Balbuena, Examination of the approximations used in determining the isosteric 647 heat of adsorption from the Clausius-Clapeyron equation, Langmuir, 14 (1998) 6323-6327. 
648 [19] V. Baroghel-Bouny, M. Mainguy, T. Lassabatere, O. Coussy, Characterization and identification of 649 equilibrium and transfer moisture properties for ordinary and high-performance cementitious materials, 650 Cement and Concrete Research, 29 (1999) 1225-1238.

651 [20] M. Mainguy, O. Coussy, V. Baroghel-Bouny, Role of air pressure in drying of weakly permeable 652 materials, Journal of Engineering Mechanics (ASCE), 127 (2001) 582-592.

653 [21] O. Coussy, Poromechanics, John Wiley \& Sons Ltd2004.

654 [22] V. Baroghel-Bouny, Water vapour sorption experiments on hardened cementitious materials. Part II. 655 Essential tool for assessment of transport properties and for durability prediction, Cement and Concrete 656 Research, 37 (2007) 438-454.

657 [23] S. Poyet, Determination of the intrinsic permeability to water of cementitious materials: influence of 658 the water retention curve, Cement and Concrete Composites, 35 (2013) 127-135.

659 [24] S. Whitaker, Simultaneous heat, mass, and momentum transfer in porous media: a theory of drying, 660 Advances in Heat Transfer, 13 (1977) 119-203.

661 [25] D. Gawin, B.A. Schrefler, Thermo-hydro-mechanical analysis of partially saturated porous materials, 662 Engineering Computations, 13 (1996) 113-143.

663 [26] J. Selih, A.C.M. Sousa, T.W. Bremner, Moisture transport in initially fully saturated concrete during 664 drying, Transport in Porous Media, 24 (1996) 81-106.

665 [27] F. Meftah, S. Dal Pont, Staggered finite volume modeling of transport phenomena in porous 666 materials with convective boundary conditions, Transport in Porous Media, 82 (2010) 275-298.

667 [28] M. Thiery, V. Baroghel-Bouny, N. Bourneton, G. Villain, C. Stéfani, Modélisation du séchage des 668 bétons, analyse des différents modes de transfert hydrique (in French), European Journal of 669 Environmental and Civil Engineering, 11 (2007) 541-577. 
670 [29] M. Thiery, P. Belin, V. Baroghel-Bouny, M.D. Nguyen, Modeling of isothermal drying process in 671 cementitious materials, analysis of the moisture transfer and proposal of simplified approaches, in: J.-F. 672 Shao, N. Burlion (Eds.) $3^{\text {rd }}$ international conference GeoProc, Wiley, Lille (France), 2008, pp. 571-579.

673 [30] L.A. Richards, Capillary conduction of liquids through porous mediums, Physics, 1 (1931) 318-333.

674 [31] B.M. Savage, D.J. Janssen, Soil physics principles validated for use in predicting unsaturated moisture 675 movement in Portland cement concrete, ACI Materials Journal, 94 (1997) 63-70.

676 [32] M.T. van Genuchten, A closed-form equation for predicting the hydraulic conductivity of 677 unsaturated soils, Soil Science Society of America Journal, 44 (1980) 892-898.

678 [33] Y. Mualem, A new model for predicting the hydraulic conductivity of unsaturated porous media, 679 Water Resources Research, 12 (1976) 513-522.

680 [34] H. Lagrave, G. Ranc, C. Gallé, S. Durand, Durability design of heated concrete structures.

681 Methodology and application to long-term interim storage, Journal de Physique IV, 136 (2006) 223-231.

682 [35] J.-P. Silvy, N. Moulin, F. Laurent, Long-term (100-300 years) interim dry storage for spent fuel:

683 package and facilities development including safety aspects and durability assessment program, in: J.D.B.

684 Lambert, K.K. Kadyrzhanov (Eds.) Safety Related Issues of Spent Nuclear Fuel Storage, Springer, 2007, pp. $685 \quad 181-188$.

686 [36] P. de Coninck, G. Ranc, J. Iacono, J.-L. Martin, N. Moulin, K. Shirai, Y. Le Pape, E. Tronche, 687 Contribution of Galatée on reinforced concretesStructurebBehavior for a full scales subsurface storage 688 laboratory, in: F. Bart, C.C.D. Coumes, F. Frizon, S. Lorent (Eds.) Proceedings of the $1^{\text {st }}$ NUWCEM 689 SymposiumAvignon (France), 2011.

690 [37] C. Cau Dit Coumes, S. Courtois, D. Nectoux, S. Leclercq, X. Bourbon, Formulating a low-alkalinity, 691 high-resistance and low-heat concrete for radioactive waste repositories, Cement and Concrete 692 Research, 36 (2006) 2152-2163. 
693 [38] M. Codina, C. Cau-dit-Coumes, P. Le Bescop, J. Verdier, J.P. Ollivier, Design and characterization of

694 low-heat and low-alkalinity cements, Cement and Concrete Research, 38 (2008) 437-448.

695 [39] R. Barneyback, S. Diamond, Expression and analysis of pore fluid from hardened psates and mortars,

696 Cement and Concrete Research, 11 (1981) 279-285.

697 [40] J. Khatib, P.S. Mangat, Absorption characteristics of concrete as a function of location relative to 698 casting position, Cement and Concrete Research, 25 (1995) 999-1010.

699 [41] J. Khatib, P.S. Mangat, Porosity of cement paste cured at $45^{\circ} \mathrm{C}$ as a function of location relative to 700 casting position, Cement and Concrete Research, 25 (2003) 97-108.

701 [42] E.E. Demirci, R. Şahin, Comparison of carbonation resistance and uniformity of SCC and CC core 702 samples, Magazine of Concrete Research, 2014, pp. 531-539.

703 [43] R.A. Olson, H.M. Jennings, Estimation of C-S-H content in a blended cement paste using water 704 adsorption, Cement and Concrete Research, 31 (2001) 351-356.

705 [44] G. Pickett, Modification of the Brunauer-Emmett-Teller theory of multimolecular adsorption, Journal 706 of the American Chemical Society, 67 (1945) 1958-1962.

707 [45] S. Brunauer, P.H. Emmett, E. Teller, Adsorption of gases in multimolecular layers, Journal of the 708 American Chemical Society, 60 (1938) 309-319.

709 [46] J.B. Condon, Surface area and porosity determinations by physisorption - Measurements \& theory, $710 \quad$ Elsevier2006

711 [47] P.H. Emmett, S. Brunauer, The Use of Low Temperature van der Waals Adsorption Isotherms in 712 Determining the Surface Area of Iron Synthetic Ammonia Catalysts, Journal of the American Chemical 713 Society, 59 (1937) 1553-1564.

714 [48] S.J. Gregg, K.S.W. Sing, Adsorption, surface area and porosity, 2nd ed ed., Academic Press, London, 715 United Kingdom, 1982. 
716 [49] L. Wadsö, K. Svennberg, A. Dueck, An experimentally simple method for measuring sorption

717 isotherms, Drying Technology, 22 (2004) 2427-2440.

718 [50] D.S. Carr, B.L. Harris, Solutions for maintaining constant relative humidity, Industrial and Engineering

719 Chemistry, 41 (1949) 2014-2015.

720 [51] A. Wexler, S. Hasegawa, Relative humidity-temperature relationships of some saturated salt

721 solutions in temperature range $0^{\circ} \mathrm{C}$ to $50^{\circ} \mathrm{C}$, Journal of Research of the National Bureau of Standards, 53

722 (1954) 19-26.

723 [52] A. Scheider, Neue dagramme zur bestimmug der relativen luftfeuchtigkeit uber gesattigten

724 wasserigen salzslosungen und wasserigen schwefelsaurelosingen bei verschiedenen temperaturen (in

725 german), Hol als Rohund Werstoff, 18 (1960) 269-272.

726 [53] J.F. Young, Humidity control in the laboratory using salt solutions - a review, Journal of Applied

727 Chemistry, 17 (1967) 241-245.

728 [54] L. Greenspan, Humidity fixed points of binary saturated aqueous solutions, Journal of Research of

729 the National Bureau of Standards - A, Physics and Chemistry, 81A (1977) 89-96.

730 [55] V. Baroghel-Bouny, Caractérisation des pâtes de ciment et des bétons : Méthodes, analyse,

731 interprétations (in french), Presses du Laboratoire Central des Ponts et Chaussées, Paris, France, 1994.

732 [56] V. Baroghel-Bouny, Water vapour sorption experiments on hardened cementitious materials: Part I.

733 Essential tool for analysis of hygral behaviour and its relation to pore structure, Cement and Concrete

734 Research, 37 (2007) 414-437.

735 [57] C. Gallé, Effect of drying on cement-based materials pore structure as identified by mercury

736 intrusion porosimetry. A comparative study between oven-, vacuum-, and freeze-drying, Cement and

737 Concrete Research, 31 (2001) 1467-1477.

738 [58] M.C. Garci Juenger, H.M. Jennings, The use of nitrogen adsorption to assess the microstructure of

739 cement paste, Cement and Concrete Research, 31 (2001) 883-892. 
740 [59] J.J. Beaudouin, B.T. Tamtsia, Effect of drying methods on microstructural changes in hardened

741 cement paste: an A.C. impedance spectroscopy evaluation, Journal of Advanced Concrete Technology, 2

742 (2004) 113-120.

743 [60] A. Korpa, R. Trettin, The influence of different drying methods on cement paste microstructures as

744 reflected by gas adsorption: comparison between freeze-drying, D-drying, P-drying and oven-drying,

745 Cement and Concrete Research, 36 (2006) 634-649.

746 [61] P.A.M. Basheer, Permeation analysis, in: V.S. Ramachandran, J.J. Beaudouin (Eds.) Handbook of

747 analytical techniques in concrete science and technlogy, Noyes Publications, Park Ridge, New Jersey,

748 U.S.A., 2001, pp. 658-737.

749 [62] W. Klemm, Ettringite and oxyanion-substituted ettringites - their characterization and applications in 750 the fixation of heavy metals: a synthesis of the literature, Portland Cement Association Research and 751 Development Bulletin RD116 (1998) 68p.

752 [63] Q. Zhou, F. Glasser, Kinetics and mechanism of the carbonation of ettringite, Advances in Cement 753 Research, 12 (200) 131-136.

754 [64] Y. Aono, F. Matsushita, S. Shibata, Y. Hama, Nano-structural changes of C-S-H in hardened cement 755 paste during drying at $50^{\circ} \mathrm{C}$, Journal of Advanced Concrete Technology, 5 (2007) 313-323.

756 [65] X. Cong, R.J. Kirkpatrick, Effects of the temperature and relative humidity on the structure of C-S-H

757 gel, Cement and Concrete Research, 25 (1995) 1237-1245.

758 [66] E. Gallucci, X. Zhang, K. Scrivener, Effect of temperature on the microstructure of calcium silicate 759 hydrate (C-S-H), Cement and Concrete Research, 53 (2013) 185-195.

760 [67] K.S.W. Sing, E. D.S., R.A.W. Haul, L. Moscou, R.A. Pierotti, J. Rouquérol, T. Siemieniewska, Reporting 761 physisorption data for gas/solid systems with special reference to the determination of surface area and porosity (Recommendations 1984), Pure and Applied Chemistry, 57 (1985) 603-619. 
764 some cookies and corn snacks, Journal of Food Engineering, 31 (1997) 85-93.

765 [69] M.M. Vivanco, O.M. Taboada, Thermodynamic behavior of fish meal during adsorption, Drying

766 Technology, 16 (1998) 1827-1842.

767 [70] I.I. Salame, T.J. Bandosz, Experimental study of water adsorption on activated carbons, Langmuir, 15 768 (1999) 587-593.

769 [71] I.I. Salame, T.J. Bandosz, Study of water adsorption on activated carbons with different degrees of 770 surface oxidation, Journal of Colloid and Interface Science, 210 (1999) 367-374.

771 [72] M. Das, S. Das, Analysis of moisture sorption characteristics of fish protein myosin, International 772 Journal of Food Science and Technology, 37 (2002) 223-227.

773 [73] N. Hamdami, J.-Y. Monteau, A. Le Bail, Transport properties of a high porosity model food at above 774 and sub-freezing temperatures. Part 1: thermophysical properties and water activity, Journal of Food 775 Engineering, 62 (2004) 373-383.

776 [74] S. Timoumi, F. Zagrouba, D. Mihoubi, M.M. Tlili, Experimental study and modelling of water 777 sorption/desorption isotherms on two agricultural products: apple and carrot, Journal de Physique IV, $778122(2004)$ 235-240.

779 [75] E. Quirjins, A. van Boxtel, W. van Loon, G. van Straten, Sorption isotherms, GAB parameters and 780 isosteric heat of sorption, Journal of the Science of Food and Agriculture, 85 (2005) 1805-1814.

781 [76] C. Pérez-Alonso, C.I. Beristain, C. Lobato-Calleros, M.E. Rodríguez-Huezo, E.J. Vernon-Carter, 782 Thermodynamic analysis of the sorption isotherms of pure and blended carbohydrate polymers, Journal 783 of Food Engineering, 77 (2006) 753-760.

784 [77] R. Feldman, P. Sereda, A model for hydrated Portland cement paste as deduced from sorption785 length change and mechanical properties, Materials and Structures, 1 (1968) 509-520. 
786 [78] H.M. Jennings, Refinements to colloid model of C-S-H in cement: CM-II, Cement and Concrete 787 Research, 38 (2008) 275-289.

788 